\title{
Mapping of serological testing and SARS- CoV-2 seroprevalence studies performed in 20 European countries, March-June 2020
}

Laura Bubba ${ }^{1}$, Peter Simmonds ${ }^{2}$, Thea K Fischer ${ }^{3,4 *}$, Heli Harvala ${ }^{5,6 *}$; on behalf of the ESCV \& ENPEN study group

\footnotetext{
${ }^{1}$ Department of Biomedical Science for Health, University of Milan, Milan, Italy

${ }^{2}$ Nuffield Department of Medicine, University of Oxford, Oxford, UK

${ }^{3}$ Department of Clinical Research, University hospital of Nordsjaelland, Hilleroed, Denmark

${ }^{4}$ Department of Public Health, University of Copenhagen, Copenhagen, Denmark

${ }^{5}$ Microbiology Services, NHS Blood and Transplant, London, UK

${ }^{6}$ Division of Infection and Immunity, University College London, London, UK

*Shared last authorship.
}

Background The SARS-CoV-2 pandemic spread across Europe from February 2020. While robust SARS-CoV-2 serological assays were quickly developed, only limited information on applied serological testing is available. We describe the extent and nature of SARS-CoV-2 serological testing used in Europe and assess the links between epidemiology, mitigation strategies applied and seroprevalence.

Methods An online questionnaire on SARS-CoV-2 serology was sent to the European Society of Clinical Virology and European Non-Polio Enterovirus Network members in September 2020. Data were analysed by comparing mitigation approaches, serological methods and seroprevalance studies performed.

Results About 100000 laboratory confirmed cases identified between March and June 2020 were reported by 36 participating laboratories from 20 countries. All responders experienced mitigation strategies including lockdowns and other closures. All except one participant had introduced serological testing; most had validated their assays $(n=29)$, but some had had difficulties in obtaining reference material. Most used commercial assays ( $\mathrm{n}=35$ ), measuring $\operatorname{Ig} G$ response against the spike antigen. Serology was used primarily for diagnostic purposes $(n=22)$ but also for convalescent plasma $(n=13)$ and research studies $(n=30)$. Seroprevalence studies targeted mainly health care workers $(n=20$; seroprevalance $5 \%$ to $22 \%)$ and general population ( $\mathrm{n}=16$; seroprevalance $0.88 \%$ to $5.6 \%$ ). Basic demographic and clinical information were collected by most laboratories $(n=28)$, whereas data on long-term outcomes were rarely collected.

Conclusions This is first study gathering systematic information on serological testing approaches implemented during the first pandemic wave in Europe.

Infection with severe acute respiratory syndrome coronavirus 2 (SARS-CoV-2) was first reported in Wuhan, China, in December 2019 [1]. It soon escalated into a pandemic which has to date as of 8 April 2021 affected more than 27 million people and been associated with more than 625000 deaths in the European region [1]. SARS-CoV-2 associated disease termed as COVID-19 ranges from asymptomatic to mild upper respiratory track and gastrointestinal symptoms, to severe pneumonia, thrombosis, multi-organ failure and death [2]. 
During the first pandemic wave in Europe, comprehensive mitigation strategies were implemented in many European countries in order to limit the spread of the novel SARS-CoV-2 and to protect health care systems from overwhelming numbers of very ill patients. These measures included national lockdowns and social isolation, enhanced border control and even closure of borders. At the same time, huge efforts were required from diagnostic virology laboratories and public health agencies to evaluate and introduce new molecular and serological methods for SARS-CoV-2 diagnostics in order to respond to the pandemic and provide on-going scientific support for the mitigation strategies introduced. For these reasons, population-based estimates for SARS-CoV-2 seroprevalence were, and still are, in high demand. Review of published data highlighted a generally low SARS-CoV-2 seroprevalence in Europe [3]. Nationwide seropositivity ranged from 2.5\% in Italy [4] and 5\% in Spain [5], despite the similar numbers of SARS-CoV-2 infections reported during the first wave [6]. However, seropositivity numbers should not be compared without adjusting for test sensitivity and specificity, highly dependent on the chosen target antigen and assay used. Furthermore, substantial variability in SARS-CoV-2 seropositivity was demonstrated in Spain. Highest seroprevalence rates exceeding 10\% were measured in the areas with high prevalence of SARS-CoV-2 infection (ie, Madrid area) and among health care workers with likely greater exposure to the virus.

Serological tests are used for many purposes including estimating population exposures, retrospective diagnostics of SARS-CoV-2 infections, and identification of convalescent plasma donations containing high levels of SARS-CoV-2 antibodies [7].

A large number of serological assays have been released into European market since the first reports of SARSCoV-2 infection in Wuhan. Commercially available serological assays can detect IgG, IgM or IgA alone or combination of all antibodies (total antibody). Existing assays target antibodies to the nucleocapsid and/or spike protein, sometimes including only the receptor-binding domain (RBD) part. Although fast development of commercial serological assays has been vital to our pandemic response, their performance including sensitivity and specificity has remained suboptimal at times [8]. However, no information is available, in our knowledge, about the European diagnostic laboratory approach to serology, including how commonly and which serological methods are used, and how these were validated. Furthermore, limited data are published on the quality of serological data collected and their completeness, which is needed in order to better understand the antibody response acquired as a result of SARS-CoV-2 infection.

We have evaluated the extent of serological SARS-CoV-2 testing and methods used in Europe so far and the quality and quantity of serological data collected during the first wave of pandemic. Mitigation and quarantine strategies applied have been also investigated in order to describe whether they affected the number of COVID-19 cases. These will provide essential European-wide baseline information which can be used to inform future policies and targeted public health strategies during the future pandemic waves and to evaluate vaccine immunization response.

\section{METHODS}

\section{Data collection}

A link to the online questionnaire was sent to all members of the European Society for Clinical Virology (ESCV) and European Non-Polio Enterovirus Network (ENPEN) in order to reach a good selection of clinical and public health virology laboratories on the European territory. One reminder letter was sent. Data were collected using the EU-survey platform. Questionnaire was opened 23rd September and closed 12th October.

Basic participant information was collected; this included whether their laboratory was performing diagnostic SARS-CoV-2 services and whether it was linked to hospital, university and/or national public health institution. The survey focused on the epidemiology of SARS-CoV-2 infections in the respondent's institution or country, and hence the number of SARS-CoV-2 infections diagnosed, and population size covered by that institution were captured (Figure 1). Data on mitigation and quarantine strategies applied were also collected. Details of serological testing methods applied in respondent's institution or country, including their details of their validation, use in diagnostic and different seroprevalence studies, was also collected. Data on serological testing performed was collected, including the estimated number of samples tested.

\section{Data analyses}

A descriptive analysis was undertaken by participant laboratory and country. The geographical distribution of laboratories by their main function in Europe were mapped.

Participant laboratories were asked to report the COVID-19 case definition in use during the study period. 


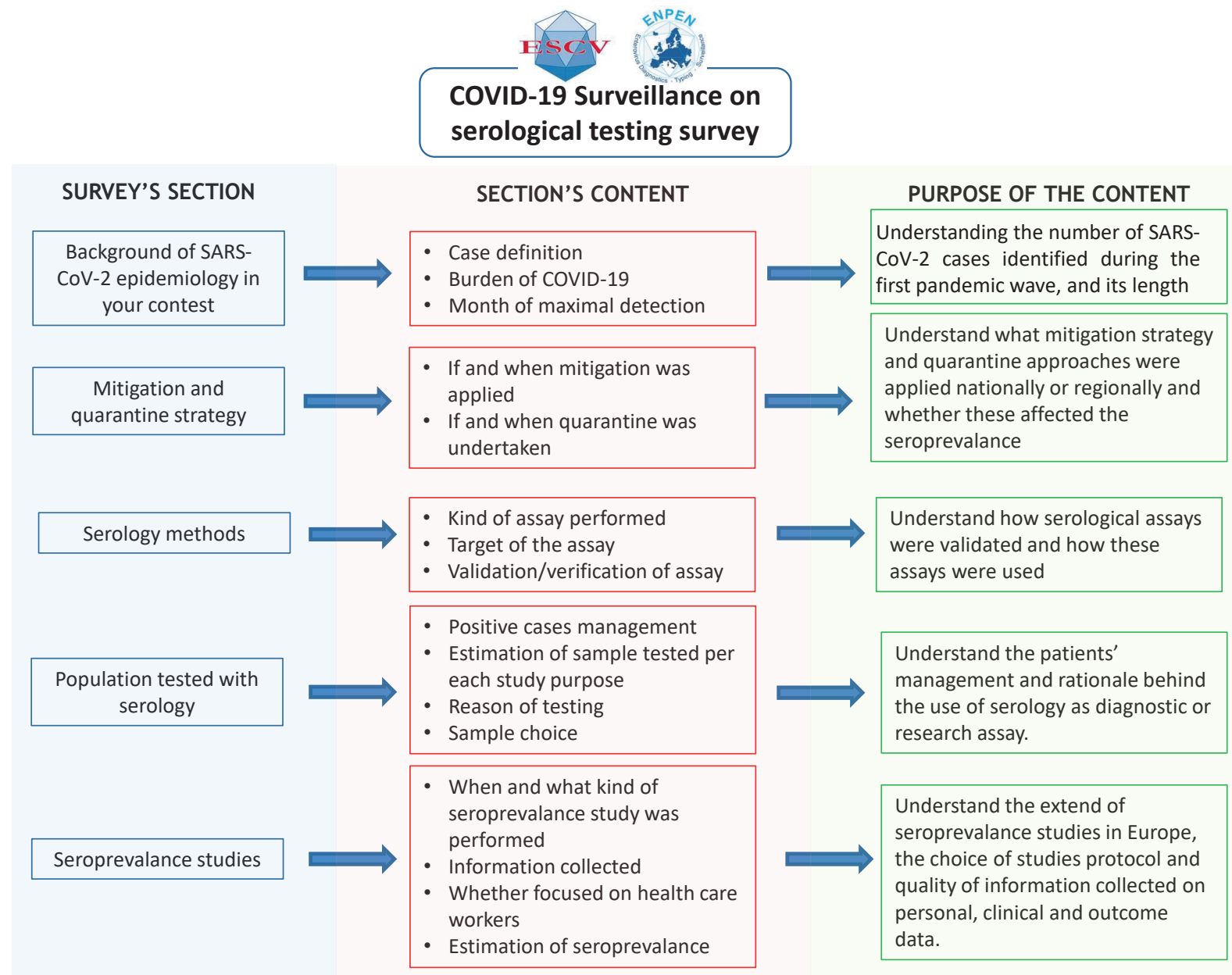

Figure 1. Survey structure divided by the five sections of the survey, their specific content and the purpose of the section.

Responders also reported, information on the month when the highest number of confirmed SARS-CoV-2 cases, and this was compared with the timing of lockdown strategy applied. The estimated number of COVID-19 cases was compared to the length of mitigation strategies applied, in order to demonstrate whether to highest number of cases corresponded to the longest period of restrictions applied.

Serological methods reported by participant laboratory were divided into virus neutralisation, commercial and in-house assays. In addition, we collected and analysed the data on targets (ie, immunoglobulin class or antigenic target) and we recorded if the laboratories has performed the validation or verification of their serological assay, and if so, using how many samples. Serological testing was categorised into clinical diagnostics, testing of convalescent plasma donor to determine which donations contained high enough SARS-CoV-2 antibody levels to be used as a treatment for COVID-19 and seroprevalence studies (ie, serology was used to drive or support studies to determine the susceptibility of the population calculating the seroprevalance in a population).

For seroprevalance studies, we collected and analysed data on study population, design and size of the study.

Laboratories performing seroprevalance studies were asked to estimate the seroprevalance as the proportion of SARS-CoV-2 seropositives by the number of inhabitants, and the study population size when possible. The proportions reported were compared, analysing whether any significant differences were observed with $\chi^{2}$ test, considering a $P<0.05$ as statistically significant.

\section{RESULTS}

A total of 36 participant laboratories from 20 countries responded to this survey (Table 1, Figure 2). Portugal was represented with 6 participant laboratories, followed by Germany, Spain and Turkey which contributed with 3 participating laboratories and Denmark, Greece, Norway, Slovenia and Sweden with two participating 
laboratories each. Austria, Belgium, Bosnia and Herzegovina, Bulgaria, Croatia, Czech Republic, Iceland, Ireland, Italy, the Netherlands and Romania participated with one laboratory each. Eight countries reported the population covered from their laboratories and/or the number of beds accounted in their hospitals. Reported population size ranged from 700 bed hospital in Istanbul to 1616 beds in Freiburg, covering approximatively from 500000 and $>1000000$ inhabitants (Table 1).

The majority of laboratories participating in the survey were involved in both diagnostic work and research (20/36, 55\%); these included university hospitals (5/20), national (9/20) or regional (3/20) public health institutes and university microbiological laboratories $(3 / 20)$. The remaining were diagnostic hospital laboratories (11/16), private laboratory (1/16) or university departments (4/16) (Table 1).

\section{Case-definition}

Thirty-three out of 36 participating laboratories reported use of the COVID-19 case definition during the study period: in most cases viral RNA detection in nasal-pharyngeal specimen or secretions taken from the respiratory tract was considered sufficient to confirm a case $(70 \%, 23 / 33)$, whereas the remaining responders defined a confirmed COVID-19 case only when clinical symptoms consistent with COVID-19 were reported in addition to molecular RNA detection $(28 \%, 9 / 33)$. Case definition was not applicable for three responders (ie, private laboratories) and one participant did not describe a case definition. Notably, as the case definition might have changed for some locations during the first wave of the pandemic, coinciding with the study period, the most recent case definition was recorded.

\section{Case numbers}

Around 100000 laboratory confirmed SARS-CoV-2 infections identified between 1st March and 31st June 2020 were reported by the 34 participant laboratories. However, it is important to note that this was an estimate only and the number of reported cases ranged from less than 10 reported by Bulgaria to more than 10000 cases reported by participating laboratories in Denmark, Portugal, Spain and Sweden (Table 1). The highest number of infections were recorded in March by 11 laboratories from 6 countries and in April by 15 laboratories from 10 countries (Table 1). Only one participating laboratory recorded a peak number of cases in May (Portugal) and five in June. No such data were obtained from 4 laboratories.

\section{Mitigation and quarantine strategies}

Mitigation and quarantine strategies were reported by 33 participants. Sweden (reported by both participating laboratories) was the only country which did not apply any mitigation or lockdown during the first pandemic wave, but were instead recommending people to keep social distancing, avoid gathering with more than 50 people and restricting the access to care homes (Table 1). 30 out of the remaining 32 participant laboratories reported a national lockdown undertaken as mitigation strategy, with varying length. For 26 participating laboratories, it was possible to compare the timing of the peak of COVID-19 case detection and implementation of mitigation measures. It was observed that the peak number of cases were recorded one month after the introduction of mitigation measures by $42 \%$ of participant laboratories (11/26), by $39 \%$ (10/26) during the first month of lockdown, by 15\% (4/26) the month after the end of lockdown and by 4\% (1/26) during the last month of these actions (Table 1). Severity of mitigation strategies, such as the length of national lockdown was not always proportional to the number of cases reported. For instance, Bulgaria reported less than 10 cases, whereas over 10000 cases were reported by the Danish participants. Despite the difference in reported number of SARS-CoV-2 infections, both countries applied four months of lockdown (Table 1). Six countries including Belgium, Croatia, Greece, Ireland, and Spain reported the use of local lockdowns in spite of the national lockdown in order to control the increasing numbers of SARS-CoV-2 infections in the affected areas (Table 1).

Most laboratories reported the use of 14-day isolation period for the close contacts of confirmed SARS-CoV-2 case (29/33) and some of them applied these also for the contacts of suspected SARS-CoV-2 case (20/33). All laboratories placed contacts into 14-day quarantine while waiting for the PCR result and that was also applied for foreign travel (17/33; Table 1).

\section{Serological assays used}

All except one laboratory had introduced at least one SARS-CoV-2 serological assay for routine work during the first pandemic wave $(n=35)$, while the remaining laboratory was planning to introduce such a test. All of them had introduced commercial assay for SARS-CoV-2 serology, and one focused on live virus neutralisation 


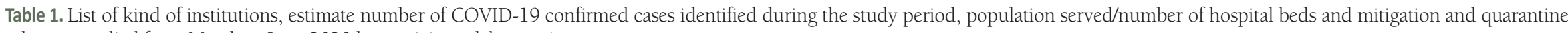
schemes applied from March to June 2020 by participant laboratories

\begin{tabular}{|c|c|c|c|c|c|c|c|c|c|c|c|c|c|c|c|c|c|c|}
\hline \multirow[b]{2}{*}{ COUNTRY } & \multirow{2}{*}{$\begin{array}{l}\text { CITY (IN } \\
\text { ORDER OF } \\
\text { SUBMISSION) }\end{array}$} & \multirow[b]{2}{*}{ INSTITUTION } & \multirow{2}{*}{$\begin{array}{l}\text { PURPOSE } \\
\text { LABORATORY } \\
\text { ACTIVITY }\end{array}$} & \multirow[b]{2}{*}{ POPULATION } & \multirow{2}{*}{$\begin{array}{c}\text { TOTAL } \\
\text { NUMBER } \\
\text { OF CASES } \\
\text { REPORTED } \\
\text { (ESTIMATE) }\end{array}$} & \multirow{2}{*}{$\begin{array}{l}\text { PEAK } \\
\text { MONTH }\end{array}$} & \multicolumn{4}{|c|}{$\begin{array}{l}\text { LOCKDOWNS } \\
\text { IMPLEMENTATION }\end{array}$} & \multicolumn{4}{|c|}{$\begin{array}{l}\text { SCHOOL, OFFICE AND } \\
\text { RESTAURANTS CLOSURE }\end{array}$} & \multicolumn{4}{|c|}{ QUARANTINE SCHEME } \\
\hline & & & & & & & $\begin{array}{l}3 \\
\frac{3}{2} \\
\frac{2}{2}\end{array}$ & $\frac{2}{3}$ & 3 & $\vec{\Xi}$ & $\begin{array}{l}\frac{3}{2} \\
\frac{a}{2}\end{array}$ & 胥. & $\frac{3}{2}$ & $\bar{\Xi}$ & $\begin{array}{l}\text { CONFIRMED } \\
\text { CLOSE } \\
\text { CONTACT }\end{array}$ & $\begin{array}{l}\text { SUSPECTED } \\
\text { CLOSE } \\
\text { CONTACT }\end{array}$ & $\begin{array}{l}\text { TRAVEL IN EU } \\
\text { COUNTRIES }\end{array}$ & $\begin{array}{l}\text { TRAVEL EXTRA } \\
\text { EU COUNTRIES }\end{array}$ \\
\hline Austria & Vienna & $\begin{array}{l}\text { Hospital and University } \\
\text { microbiology laboratory }\end{array}$ & $\begin{array}{l}\text { Diagnostic } \\
\text { and research }\end{array}$ & Not reported & 101-1000 & March & $*$ & $*$ & $* *$ & $* *$ & II & II & q & $* *$ & $\begin{array}{l}<14 \mathrm{~d}, \\
\text { depending on } \\
\text { swab results }\end{array}$ & $\begin{array}{l}<14 \mathrm{~d} \text {, } \\
\text { depending on } \\
\text { swab results }\end{array}$ & $<14 \mathrm{~d}, 14 \mathrm{~d}$ & $<14 \mathrm{~d}, 14 \mathrm{~d}$ \\
\hline Belgium & Bruges & $\begin{array}{l}\text { Hospital microbiology } \\
\text { laboratory }\end{array}$ & Diagnostic & Not reported & $1000-5000$ & April & $*$ & $*$ & $* *$ & $\neq$ & ** & $* *$ & ** & I & $\begin{array}{l}14 \mathrm{~d} \text {, } \\
\text { depending on } \\
\text { swab results }\end{array}$ & & $14 \mathrm{~d}$ & $14 \mathrm{~d}$ \\
\hline $\begin{array}{l}\text { Bosnia and } \\
\text { Herzigovina }\end{array}$ & Sarajevo & $\begin{array}{l}\text { Hospital and University } \\
\text { microbiology laboratory }\end{array}$ & $\begin{array}{l}\text { Diagnostic } \\
\text { and research }\end{array}$ & $\begin{array}{l}1331310 \\
\text { people; } 1464 \\
\text { beds }\end{array}$ & $1000-5000$ & June & - & $*$ & $*$ & $* *$ & $* *$ & I & q & $\S$ & $14 \mathrm{~d}$ & & & \\
\hline Bulgaria & Sofia & $\begin{array}{l}\text { National public health } \\
\text { institute }\end{array}$ & $\begin{array}{l}\text { Diagnostic } \\
\text { and research }\end{array}$ & Not reported & $<10$ & $\begin{array}{l}\text { Not } \\
\text { reported }\end{array}$ & $*$ & $*$ & $*$ & $*$ & II & I & q & q & $\begin{array}{l}>14 \mathrm{~d} \text {, } \\
\text { depending } \\
\text { swab/sero } \\
\text { results }\end{array}$ & $\begin{array}{c}14 \mathrm{~d}, \\
\text { depending } \\
\text { swab/sero } \\
\text { results }\end{array}$ & $\begin{array}{l}14 \mathrm{~d}, \\
\text { depending } \\
\text { swab/sero } \\
\text { results }\end{array}$ & $\begin{array}{l}14 \mathrm{~d}, \\
\text { depending } \\
\text { swab/sero } \\
\text { results }\end{array}$ \\
\hline Croatia & Zagreb & $\begin{array}{l}\text { National public health } \\
\text { institute }\end{array}$ & $\begin{array}{l}\text { Diagnostic } \\
\text { and research }\end{array}$ & Not reported & $1000-5000$ & April & * & $*$ & * & $\neq$ & II & I & q & $\S$ & $\begin{array}{c}14 \mathrm{~d} \\
\text { depending on } \\
\text { swab results }\end{array}$ & & $14 \mathrm{~d}$ & $14 \mathrm{~d}$ \\
\hline $\begin{array}{l}\text { Czech } \\
\text { Republic }\end{array}$ & Prague & $\begin{array}{l}\text { National public health } \\
\text { institute }\end{array}$ & $\begin{array}{l}\text { Diagnostic } \\
\text { and research }\end{array}$ & Not reported & 101-1000 & April & $*$ & * & * & - & II & I & II & $* *$ & $<14 d$ & $\begin{array}{c}\text { Depending on } \\
\text { swab results }\end{array}$ & $14 \mathrm{~d}$ & $14 \mathrm{~d}$ \\
\hline \multirow[b]{2}{*}{ Denmark } & Copenhagen & $\begin{array}{l}\text { Hospital microbiology } \\
\text { laboratory }\end{array}$ & Diagnostic & $\begin{array}{l}>1000000 \\
\text { people }\end{array}$ & $1000-5000$ & April & $*$ & * & $*$ & $\neq$ & II & I & II & q & $14 \mathrm{~d}$ & $14 \mathrm{~d}$ & $14 \mathrm{~d}$ & $14 \mathrm{~d}$ \\
\hline & $\begin{array}{l}\text { Copenhagen } \\
\text { and Hilleroed }\end{array}$ & $\begin{array}{l}\text { National public health } \\
\text { institute; University } \\
\text { laboratory or research unit }\end{array}$ & $\begin{array}{l}\text { Diagnostic } \\
\text { and research }\end{array}$ & Not reported & $>10000$ & March & $*$ & * & $*$ & $*$ & q & II & II & 1 & $14 \mathrm{~d}$ & $\begin{array}{c}14 \mathrm{~d} \text {, } \\
\text { depending on } \\
\text { swab results }\end{array}$ & $14 \mathrm{~d}$ & $14 \mathrm{~d}$ \\
\hline \multirow{3}{*}{ Germany } & Kiel & $\begin{array}{l}\text { Regional public health } \\
\text { institute; Hospital and } \\
\text { University microbiology } \\
\text { laboratory }\end{array}$ & $\begin{array}{l}\text { Diagnostic } \\
\text { and research }\end{array}$ & Not reported & $10-100$ & March & $*$ & * & $* *$ & $* *$ & II & I & $\S$ & $* *$ & $14 \mathrm{~d}$ & $\begin{array}{l}\text { Depending on } \\
\text { swab results }\end{array}$ & $14 \mathrm{~d}$ & $14 \mathrm{~d}$ \\
\hline & Freiburg & $\begin{array}{l}\text { Hospital and University } \\
\text { microbiology laboratory }\end{array}$ & $\begin{array}{l}\text { Diagnostic } \\
\text { and research }\end{array}$ & 1616 beds & 101-1000 & April & $*$ & * & $* *$ & $* *$ & $* *$ & $* *$ & $* *$ & & $\begin{array}{c}14 \mathrm{~d}, \\
\text { depending on } \\
\text { swab results }\end{array}$ & $\begin{array}{c}\text { Depending on } \\
\text { swab results }\end{array}$ & & \\
\hline & Bonn & $\begin{array}{l}\text { University microbiology } \\
\text { laboratory }\end{array}$ & Research & Not reported & $101-1000$ & March & $*$ & * & $* *$ & $* *$ & q & q & $* *$ & & $14 \mathrm{~d}$ & & $14 \mathrm{~d}$ & $14 \mathrm{~d}$ \\
\hline \multirow{2}{*}{ Greece } & Thessaloniki & $\begin{array}{l}\text { University microbiology } \\
\text { laboratory }\end{array}$ & $\begin{array}{l}\text { Diagnostic } \\
\text { and research }\end{array}$ & Not reported & 101-1000 & April & $*$ & $*$ & * & $\neq$ & $* *$ & I & II & q & $14 \mathrm{~d}$ & $14 \mathrm{~d}$ & $14 \mathrm{~d}$ & $14 \mathrm{~d}$ \\
\hline & Crete & $\begin{array}{l}\text { Regional public health } \\
\text { institute }\end{array}$ & $\begin{array}{l}\text { Diagnostic } \\
\text { and research }\end{array}$ & 1640 beds & $10-100$ & June & $*$ & * & $*$ & $* *$ & $* *$ & $* *$ & $* *$ & $* *$ & $14 \mathrm{~d}$ & $14 \mathrm{~d}$ & $14 \mathrm{~d}$ & $14 \mathrm{~d}$ \\
\hline
\end{tabular}


Table 1. Continued

\begin{tabular}{|c|c|c|c|c|c|c|c|c|c|c|c|c|c|c|c|c|c|c|}
\hline \multirow[b]{2}{*}{ COUNTRY } & \multirow{2}{*}{$\begin{array}{l}\text { CITY (IN } \\
\text { ORDER OF } \\
\text { SUBMISSION) }\end{array}$} & \multirow[b]{2}{*}{ INSTITUTION } & \multirow{2}{*}{$\begin{array}{l}\text { PURPOSE } \\
\text { LABORATORY } \\
\text { ACTIVITY }\end{array}$} & \multirow[b]{2}{*}{ POPULATION } & \multirow{2}{*}{$\begin{array}{c}\text { TOTAL } \\
\text { NUMBER } \\
\text { OF CASES } \\
\text { REPORTED } \\
\text { (ESTIMATE) }\end{array}$} & \multirow[b]{2}{*}{$\begin{array}{l}\text { PEAK } \\
\text { MONTH }\end{array}$} & \multicolumn{4}{|c|}{$\begin{array}{l}\text { LOCKDOWNS } \\
\text { IMPLEMENTATION }\end{array}$} & \multicolumn{4}{|c|}{$\begin{array}{l}\text { SCHOOL, OFFICE AND } \\
\text { RESTAURANTS CLOSURE }\end{array}$} & \multicolumn{4}{|c|}{ QUARANTINE SCHEME } \\
\hline & & & & & & & $\begin{array}{l}\frac{3}{2} \\
\frac{2}{3}\end{array}$ & ? & $\frac{3}{20}$ & $\bar{\Xi}$ & $\begin{array}{l}\frac{3}{2} \\
\hat{3}\end{array}$ & 㿣. & $\frac{3}{2}$ & $\bar{\Xi}$ & $\begin{array}{l}\text { CONFIRMED } \\
\text { CLOSE } \\
\text { CONTACT }\end{array}$ & $\begin{array}{l}\text { SUSPECTED } \\
\text { CLOSE } \\
\text { CONTACT }\end{array}$ & $\begin{array}{l}\text { TRAVEL IN EU } \\
\text { COUNTRIES }\end{array}$ & $\begin{array}{l}\text { TRAVEL EXTRA } \\
\text { EU COUNTRIES }\end{array}$ \\
\hline Iceland & Reykjavík & $\begin{array}{l}\text { Hospital microbiology } \\
\text { laboratory }\end{array}$ & Diagnostic & Not reported & $1000-5000$ & March & $* *$ & ** & $* *$ & $* *$ & 1 & I & $* *$ & $* *$ & $14 \mathrm{~d}$ & $14 \mathrm{~d}$ & $14 \mathrm{~d}$ & $14 \mathrm{~d}$ \\
\hline Ireland & Dublin & $\begin{array}{l}\text { Hospital microbiology } \\
\text { laboratory }\end{array}$ & Diagnostic & Not reported & $1000-5000$ & April & $*$ & $*$ & * & $\ddagger$ & $* *$ & $* *$ & $* *$ & $* *$ & $14 \mathrm{~d}$ & $14 \mathrm{~d}$ & $14 \mathrm{~d}$ & $14 \mathrm{~d}$ \\
\hline Italy & Pavia & $\begin{array}{l}\text { Regional public health } \\
\text { institute; University } \\
\text { laboratory or research unit }\end{array}$ & $\begin{array}{l}\text { Diagnostic } \\
\text { and research }\end{array}$ & Not reported & $\begin{array}{l}5000- \\
10000\end{array}$ & March & $*$ & $*$ & * & $* *$ & II & II & qI & $\S$ & $\begin{array}{c}14 \mathrm{~d}, \\
\text { depending } \\
\text { swab/sero } \\
\text { results }\end{array}$ & $\begin{array}{c}14 \mathrm{~d} \\
\text { depending } \\
\text { swab/sero } \\
\text { results }\end{array}$ & $\begin{array}{l}14 \mathrm{~d}, \\
\text { depending } \\
\text { swab/sero } \\
\text { results }\end{array}$ & $\begin{array}{l}14 \mathrm{~d}, \\
\text { depending } \\
\text { swab/sero } \\
\text { results }\end{array}$ \\
\hline $\begin{array}{l}\text { The } \\
\text { Netherlands }\end{array}$ & Tilburg & $\begin{array}{l}\text { Hospital microbiology } \\
\text { laboratory }\end{array}$ & Diagnostic & $\begin{array}{l}5000000 \\
\text { people; } 1000 \\
\text { beds }\end{array}$ & $1000-5000$ & April & $*$ & $*$ & $* *$ & $* *$ & II & $\mathbb{T}$ & $* *$ & $* *$ & $\begin{array}{l}14 \mathrm{~d}, \\
\text { depending } \\
\text { swab/sero } \\
\text { results }\end{array}$ & $\begin{array}{c}14 \mathrm{~d}, \\
\text { depending } \\
\text { swab/sero } \\
\text { results }\end{array}$ & $<14 d$ & $<14 d$ \\
\hline \multirow[t]{2}{*}{ Norway } & Oslo & $\begin{array}{l}\text { Hospital and University } \\
\text { microbiology laboratory }\end{array}$ & $\begin{array}{l}\text { Diagnostic } \\
\text { and research }\end{array}$ & Not reported & $1000-5000$ & March & $*$ & $*$ & $* *$ & $* *$ & qI & II & $* *$ & $* *$ & $14 \mathrm{~d}$ & $\begin{array}{c}14 \mathrm{~d} \text {, } \\
\text { depending on } \\
\text { swab results }\end{array}$ & $<14 d$ & $<14 d$ \\
\hline & Trondheim & $\begin{array}{l}\text { Hospital microbiology } \\
\text { laboratory }\end{array}$ & Diagnostic & $\begin{array}{l}470.000 \\
\text { people }\end{array}$ & $101-1000$ & March & $*$ & $*$ & $* *$ & $* *$ & qI & $\mathbb{T}$ & $* *$ & $* *$ & $14 \mathrm{~d}$ & $14 \mathrm{~d}$ & $14 \mathrm{~d}$ & $14 \mathrm{~d}$ \\
\hline \multirow{6}{*}{ Portugal } & Porto & $\begin{array}{l}\text { University microbiology } \\
\text { laboratory }\end{array}$ & Research & Not reported & $\begin{array}{l}\text { Not } \\
\text { reported }\end{array}$ & $\begin{array}{l}\text { Not } \\
\text { reported }\end{array}$ & $*$ & $*$ & * & $* *$ & II & $\mathbb{T}$ & II & $* *$ & $14 \mathrm{~d}$ & $14 \mathrm{~d}$ & & \\
\hline & Mora & $\begin{array}{l}\text { University laboratory or } \\
\text { research unit; Community } \\
\text { Pharmacy }\end{array}$ & $\begin{array}{l}\text { Diagnostic } \\
\text { and research }\end{array}$ & Not reported & $10-100$ & $\begin{array}{l}\text { Not } \\
\text { reported }\end{array}$ & \multicolumn{8}{|c|}{ Not reported } & $14 \mathrm{~d}$ & $14 \mathrm{~d}$ & $\begin{array}{c}\text { Depending } \\
\text { on swab } \\
\text { results } \\
\end{array}$ & $\begin{array}{c}\text { Depending on } \\
\text { swab results }\end{array}$ \\
\hline & Lisbon 1 & $\begin{array}{l}\text { National public health } \\
\text { institute; Hospital and } \\
\text { University microbiology } \\
\text { laboratory }\end{array}$ & $\begin{array}{l}\text { Diagnostic } \\
\text { and research }\end{array}$ & Not reported & $101-1000$ & April & $*$ & $* *$ & $* *$ & $* *$ & II & qI & $* *$ & $* *$ & $14 \mathrm{~d}$ & $14 \mathrm{~d}$ & $\begin{array}{l}\text { Depending } \\
\text { on swab } \\
\text { results }\end{array}$ & $\begin{array}{c}\text { Depending on } \\
\text { swab results }\end{array}$ \\
\hline & Lisbon 2 & $\begin{array}{l}\text { National Institute of } \\
\text { Health }\end{array}$ & $\begin{array}{l}\text { Diagnostic } \\
\text { and research }\end{array}$ & Not reported & $>10000$ & May & $*$ & $*$ & * & $* *$ & TI & II & II & $* *$ & $14 \mathrm{~d}$ & $14 \mathrm{~d}$ & $\begin{array}{l}\text { Depending } \\
\text { on swab } \\
\text { results } \\
\end{array}$ & $\begin{array}{c}\text { Depending on } \\
\text { swab results }\end{array}$ \\
\hline & Porto & $\begin{array}{l}\text { National public health } \\
\text { institute }\end{array}$ & $\begin{array}{l}\text { Diagnostic } \\
\text { and research }\end{array}$ & Not reported & $10-100$ & April & $*$ & $*$ & $* *$ & $* *$ & II & $\mathbb{I}$ & II & $\S$ & $14 \mathrm{~d}$ & & & \\
\hline & Penafiel & $\begin{array}{l}\text { Private Laboratory Clinical } \\
\text { Analysis }\end{array}$ & Diagnostic & Not reported & 101-1000 & June & $*$ & $*$ & * & $* *$ & II & $\mathbb{I}$ & q & $* *$ & $14 \mathrm{~d}$ & $14 \mathrm{~d}$ & & \\
\hline
\end{tabular}


Table 1. Continued

\begin{tabular}{|c|c|c|c|c|c|c|c|c|c|c|c|c|c|c|c|c|c|c|}
\hline \multirow[b]{2}{*}{ COUNTRY } & \multirow{2}{*}{$\begin{array}{l}\text { CITY (IN } \\
\text { ORDER OF } \\
\text { SUBMISSION) }\end{array}$} & \multirow[b]{2}{*}{ INSTITUTION } & \multirow{2}{*}{$\begin{array}{l}\text { PURPOSE } \\
\text { LABORATORY } \\
\text { ACTIVITY }\end{array}$} & \multirow[b]{2}{*}{ POPULATION } & \multirow{2}{*}{$\begin{array}{c}\text { TOTAL } \\
\text { NUMBER } \\
\text { OF CASES } \\
\text { REPORTED } \\
\text { (ESTIMATE) }\end{array}$} & \multirow[b]{2}{*}{$\begin{array}{l}\text { PEAK } \\
\text { MONTH }\end{array}$} & \multicolumn{4}{|c|}{$\begin{array}{l}\text { LOCKDOWNS } \\
\text { IMPLEMENTATION }\end{array}$} & \multicolumn{4}{|c|}{$\begin{array}{l}\text { SCHOOL, OFFICE AND } \\
\text { RESTAURANTS CLOSURE }\end{array}$} & \multicolumn{4}{|c|}{ QUARANTINE SCHEME } \\
\hline & & & & & & & 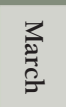 & 总 & $\underset{2}{2}$ & $\bar{\Xi}$ & $\begin{array}{l}3 \\
\stackrel{2}{2} \\
\stackrel{2}{2}\end{array}$ & ?. & $\frac{3}{2}$ & $\bar{\Xi}$ & $\begin{array}{l}\text { CONFIRMED } \\
\text { CLOSE } \\
\text { CONTACT }\end{array}$ & $\begin{array}{l}\text { SUSPECTED } \\
\text { CLOSE } \\
\text { CONTACT }\end{array}$ & $\begin{array}{l}\text { TRAVEL IN EU } \\
\text { COUNTRIES }\end{array}$ & $\begin{array}{l}\text { TRAVEL EXTRA } \\
\text { EU COUNTRIES }\end{array}$ \\
\hline Romania & Bucharest & $\begin{array}{l}\text { Hospital microbiology } \\
\text { laboratory }\end{array}$ & Diagnostic & Not reported & $\begin{array}{l}5000- \\
10000 \\
\end{array}$ & June & * & $*$ & $* *$ & $* *$ & q & q & q & II & $14 \mathrm{~d}$ & $\begin{array}{c}\text { Depending on } \\
\text { swab results }\end{array}$ & $14 \mathrm{~d}$ & $14 \mathrm{~d}$ \\
\hline \multirow[t]{2}{*}{ Slovenia } & Ljubljana 1 & $\begin{array}{l}\text { Diagnostic laboratory at } \\
\text { the National public health } \\
\text { institute }\end{array}$ & $\begin{array}{l}\text { Diagnostic } \\
\text { and research }\end{array}$ & Not reported & $10-100$ & April & * & * & $* *$ & $* *$ & q & q & $* *$ & $* *$ & $14 \mathrm{~d}$ & & $14 \mathrm{~d}$ & $14 \mathrm{~d}$ \\
\hline & Ljubljana 2 & $\begin{array}{l}\text { Academic diagnostic } \\
\text { microbiology laboratory }\end{array}$ & $\begin{array}{l}\text { Diagnostic } \\
\text { and research }\end{array}$ & Not reported & $101-1000$ & March & * & $*$ & $* *$ & $* *$ & II & II & $* *$ & $* *$ & $<14 d$ & & $<14 d$ & $<14 d$ \\
\hline \multirow{3}{*}{ Spain } & Barcelona 1 & $\begin{array}{l}\text { Hospital microbiology } \\
\text { laboratory }\end{array}$ & Diagnostic & Not reported & $1000-5000$ & March & * & $*$ & * & $* *$ & II & q & q & $\S$ & $14 \mathrm{~d}$ & $14 \mathrm{~d}$ & & \\
\hline & Barcelona 2 & $\begin{array}{l}\text { Hospital microbiology } \\
\text { laboratory }\end{array}$ & Diagnostic & $\begin{array}{l}450000 \\
\text { people; } 1200 \\
\text { beds }\end{array}$ & $>10000$ & March & $*$ & $*$ & $\ddagger$ & 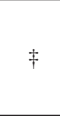 & q & q & q & $\S$ & $14 \mathrm{~d}$ & $14 \mathrm{~d}$ & & \\
\hline & Madrid & $\begin{array}{l}\text { National public health } \\
\text { institute }\end{array}$ & $\begin{array}{l}\text { Diagnostic } \\
\text { and research }\end{array}$ & Not reported & $\begin{array}{c}\text { Not } \\
\text { reported }\end{array}$ & $\begin{array}{c}\text { Not } \\
\text { reported }\end{array}$ & \multicolumn{8}{|c|}{ Not reported } & \multicolumn{4}{|c|}{ Not reported } \\
\hline \multirow{2}{*}{ Sweden } & Stockholm & $\begin{array}{l}\text { Hospital microbiology } \\
\text { laboratory }\end{array}$ & Diagnostic & Not reported & $>10000$ & April & \multirow{2}{*}{\multicolumn{8}{|c|}{$\begin{array}{l}\text { Recommendations on social distancing ie, working } \\
\text { from home, max allowed gatherings } 50 \text { people, } \\
\text { restricted access to caring facilities }\end{array}$}} & \multicolumn{4}{|c|}{ Not reported } \\
\hline & Lund & $\begin{array}{l}\text { Hospital microbiology } \\
\text { laboratory }\end{array}$ & Diagnostic & Not reported & $1000-5000$ & June & & & & & & & & & \multicolumn{4}{|c|}{ Not reported } \\
\hline \multirow{3}{*}{ Turkey } & Istanbul & $\begin{array}{l}\text { Hospital and University } \\
\text { microbiology laboratory }\end{array}$ & $\begin{array}{l}\text { Diagnostic } \\
\text { and research }\end{array}$ & 700 beds & $\begin{array}{l}5000- \\
10000\end{array}$ & April & * & * & * & $* *$ & q & II & q & $* *$ & $14 \mathrm{~d}$ & $\begin{array}{l}\text { Depending on } \\
\text { swab results }\end{array}$ & $14 \mathrm{~d}$ & $14 \mathrm{~d}$ \\
\hline & Izmir & $\begin{array}{l}\text { University microbiology } \\
\text { laboratory }\end{array}$ & Research & 1809 beds & 101-1000 & April & $* *$ & $*$ & $*$ & $*$ & II & q & q & II & $14 \mathrm{~d}$ & $14 \mathrm{~d}$ & $14 \mathrm{~d}$ & $14 \mathrm{~d}$ \\
\hline & Ankara & $\begin{array}{l}\text { University microbiology } \\
\text { laboratory }\end{array}$ & Diagnostic & 1040 beds & $1000-5000$ & April & $* *$ & $\dagger$ & $\dagger$ & $* *$ & $* *$ & q & q & II & $\begin{array}{l}14 \mathrm{~d} \text {, } \\
\text { depending on } \\
\text { swab results }\end{array}$ & $14 \mathrm{~d}$ & $14 \mathrm{~d}$ & $14 \mathrm{~d}$ \\
\hline
\end{tabular}

d-day

*National, Regional and Local lockdowns.

$\uparrow$ Regional and local lockdowns.

¥Local lockdowns only.

$\S$ School and office closure.

| Restaurant closure.

IS chool, office and restaurant closure.

**No lockdown and/or closures applied. 


\section{Geographical distribution of participants and institutions' SARS-CoV-2 service}
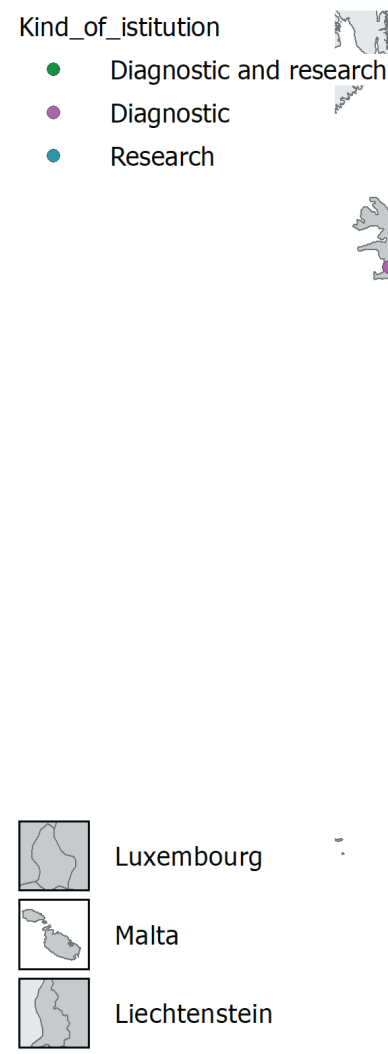

Luxembourg

Malta

Liechtenstein
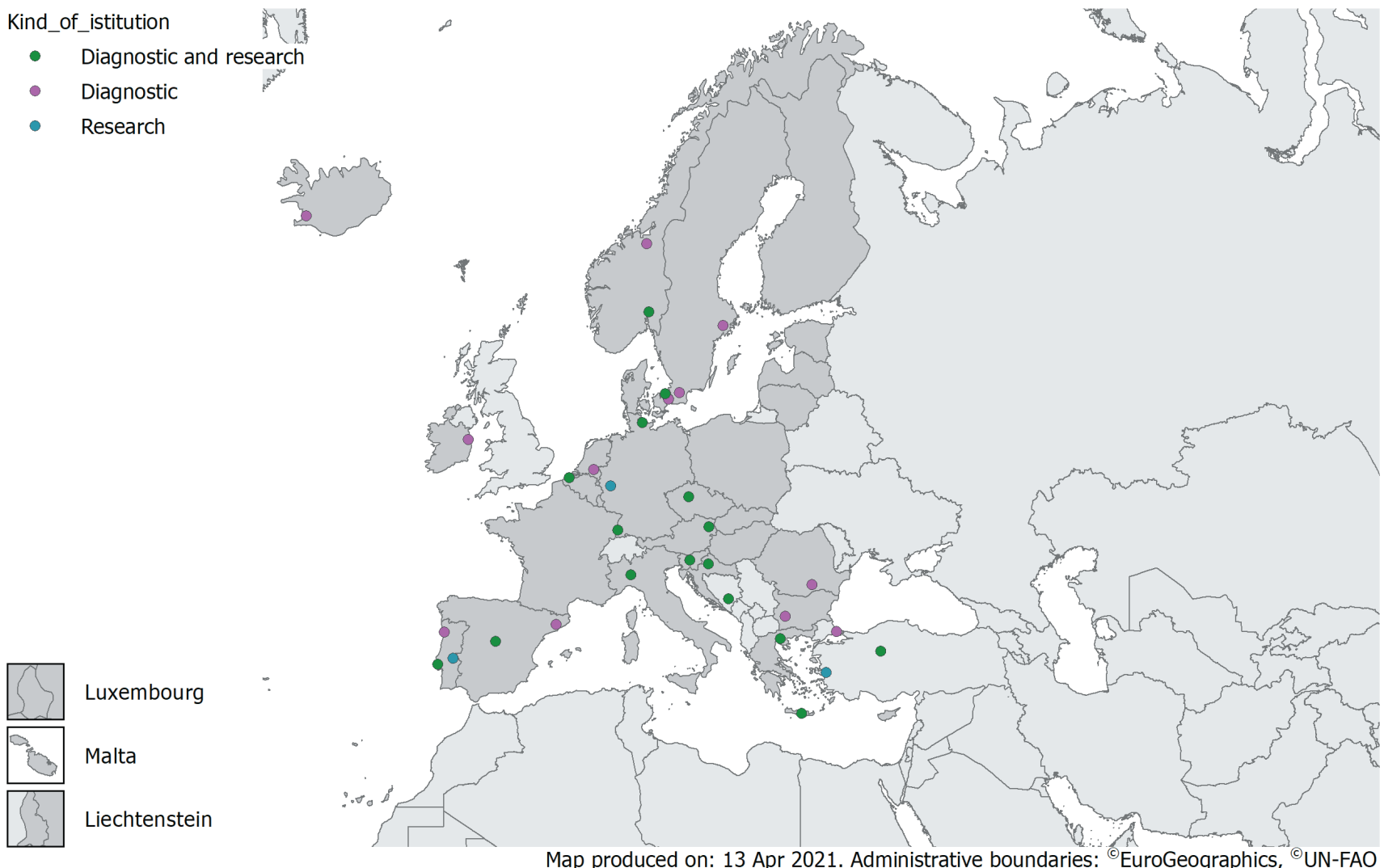

Figure 2. Map of the 36 collaborating laboratories divided by purpose of laboratory work: 1) "diagnostic and research" (in green) include all laboratories belonging to university hospitals or hospitals including a research section; 2) "diagnostic" (in violet) include all hospital laboratories, private laboratories and national/regional reference centres that operate also as diagnostic laboratory; 3) "research" (in blue) consist of all university sites and laboratory mainly dedicated to research projects

testing (Kiel; Table 2). Among the commercial assays performed, Euroimmun ELISA was the most common (17 participating laboratories from 36), followed by Roche $(n=12)$, Abbott $(n=10)$, Diasorin $(n=7)$ and Wantai $(\mathrm{n}=7$; Table 2$)$. Three laboratories used in-house assays and nine were performing neutralising antibody testing in addition to the commercial methods. These included neutralisation testing using live virus $(\mathrm{n}=7$; three laboratories in Germany, one in Croatia, Italy and Norway), pseudotype (Ireland) or other surrogate neutralising antibody testing (Spain, Table 2).

Each laboratory using commercial or in-house serological assays reported availability to measure IgG response alone (3/36 laboratories) or together with other immunoglobulins (27/36); further testing included IgM (23/36) or IgA antibodies (12/36). Assays targeted most often the spike protein $(S, n=12)$ but also nucleoprotein $(N$, $\mathrm{n}=10$ ) or receptor binding domain of spike protein (RBD, $\mathrm{n}=8)$. Only two laboratory reported availability to measure antibody responses against all three target proteins (Austria and one Slovenian laboratory, Table 2).

\section{Assay validation}

29 out of 36 laboratories reported that their method had been validated before introduction into clinical use. Among the remaining seven laboratories, two reported that the internal validation performed by their testing system was sufficient enough for them and hence no further assessment was required. Two laboratories could not identify sufficient control material for validation, one relied on published validation data on the methods selected for use and one decided to introduce the emergency test for convalescent plasma donor screening without validation. The number of known positive and negative samples included in validation work varied from one sample each to over 500 samples. Four laboratories (14\%) had included fewer than 15 samples in their validation panel.

Most laboratories reported the use of serum samples only (20 from 34 responses), whereas 12 laboratories also accepted plasma, one saliva and one plasma and saliva in addition to serum. Only one laboratory was limited to using plasma or capillary blood only. 


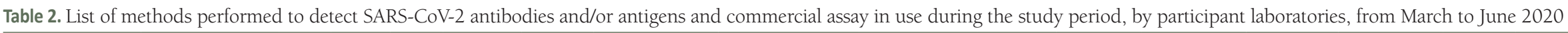

\begin{tabular}{|c|c|c|c|c|c|c|c|c|c|c|c|c|c|c|c|c|c|}
\hline \multirow{2}{*}{ COUNTRY } & \multirow{2}{*}{ CITY } & \multicolumn{4}{|c|}{ ANTIBODY DETECTION } & \multicolumn{3}{|c|}{ ANTIGENS } & \multirow{2}{*}{$\begin{array}{l}\text { LIVE VIRUS NEU- } \\
\text { TRALISATION ASSAY }\end{array}$} & \multicolumn{7}{|c|}{ COMMERCIAL ASSAY DETAILS } & \multirow{2}{*}{$\begin{array}{l}\text { IN-HOUS: } \\
\text { ASSAYS }\end{array}$} \\
\hline & & $\operatorname{IgG}$ & IgM & $\operatorname{Ig} A$ & Total Ig & Spike & RBD & $\mathrm{N}$ & & Euroimmun & Roche & Abbott & Diasorin & Wantai & NovaTec & Other & \\
\hline Austria & Vienna & $\times$ & $\times$ & $\times$ & $\times$ & $x$ & $\times$ & $x$ & $x$ & $x$ & $x$ & & & $x$ & & $x$ & $x$ \\
\hline Belgium & Bruges & $x$ & $x$ & & & $x$ & & $x$ & & $x$ & & $x$ & & & $x$ & $x$ & \\
\hline $\begin{array}{l}\text { Bosnia and } \\
\text { Herzegovina }\end{array}$ & Sarajevo & $\times$ & $x$ & & & & $x$ & & & & & & & & & $x$ & \\
\hline Bulgaria & Sofia & $x$ & $x$ & $x$ & & & $\times$ & & & $x$ & & & & & & & \\
\hline Croatia & Zagreb & $x$ & $x$ & $x$ & & $x$ & & $x$ & $x$ & $x$ & & $x$ & & & $x$ & $x$ & \\
\hline Czech Republic & Prague & $x$ & $x$ & $x$ & & & $x$ & $x$ & & $x$ & & & & & & & \\
\hline \multirow[b]{2}{*}{ Denmark } & Copenhagen & $x$ & $x$ & & & & & & & & & & & & & $x$ & \\
\hline & $\begin{array}{l}\text { Copenhagen and } \\
\text { Hilleroed }\end{array}$ & $x$ & $x$ & & & & & & & & & & & $x$ & & & \\
\hline \multirow{3}{*}{ Germany } & Kiel & & & & & & & & $\times[9]$ & & & No cc & mercial kit & & & & \\
\hline & Freiburg & $x$ & 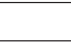 & & & & & & $x$ & $x$ & & & & & & & $x$ \\
\hline & Bonn & $x$ & $x$ & $x$ & $x$ & & & $x$ & $x$ & $x$ & $x$ & $x$ & & $x$ & & $x$ & \\
\hline \multirow{2}{*}{ Greece } & Thessaloniki & $x$ & $x$ & $x$ & $x$ & & & & & & & & & & $x$ & $x$ & \\
\hline & Crete & & & & Not repor & & & & & $x$ & & & & & & & \\
\hline Iceland & Reykjavík & & & & Not repor & & & & & & $x$ & & & & & & \\
\hline Ireland & Dublin & $x$ & $x$ & & & & & 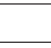 & $x^{*}$ & & & $x$ & $x$ & $x$ & & & \\
\hline Italy & Pavia & & & & $x$ & $x$ & & $x$ & $x$ & & & & $x$ & & & & \\
\hline $\begin{array}{l}\text { The } \\
\text { Netherlands }\end{array}$ & Tilburg & & & & $x$ & & $x$ & & & & & & & $x$ & & & \\
\hline \multirow{2}{*}{ Norway } & Oslo & $x$ & $x$ & $x$ & $x$ & $x$ & $x$ & - & - & $x$ & $x$ & & $x$ & & & $x$ & \\
\hline & Trondheim & & & & $x$ & & $\times$ & $x$ & $x$ & & $x$ & & & $x$ & & & \\
\hline \multirow{6}{*}{ Portugal } & Porto & $x$ & $x$ & & & & & & & & & $x$ & & & & & \\
\hline & Mora & $x$ & $x$ & & & & & & & & & $x$ & & & & & \\
\hline & Lisbon 1 & $x$ & $x$ & & & & & & & & $x$ & & $x$ & & & & \\
\hline & Lisbon 2 & $x$ & $x$ & $x$ & $x$ & $x$ & $x$ & & & $x$ & & & & $x$ & & & \\
\hline & Porto & $x$ & $x$ & & & & & 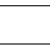 & & & & & & & & $\times$ & \\
\hline & Penafiel & $x$ & 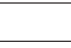 & & & & & & & & & $x$ & & & & 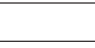 & \\
\hline Romania & Bucharest & $x$ & $x$ & & & & & & & & & & & & & $x$ & \\
\hline \multirow{2}{*}{ Slovenia } & Ljubljana 1 & $x$ & $x$ & $x$ & & $x$ & & $x$ & & $x$ & & & & & & $x$ & \\
\hline & Ljubljana 2 & $x$ & $x$ & $x$ & $x$ & $x$ & $\times$ & $\times$ & $\times$ & $x$ & $x$ & & & & & & \\
\hline \multirow{3}{*}{ Spain } & Barcelona 1 & $x$ & $x$ & & & & & & & & & $x$ & & & $x$ & & \\
\hline & Barcelona 2 & $x$ & & $x$ & $x$ & $x$ & & $x$ & & $x$ & $x$ & & $x$ & & & & \\
\hline & Madrid & $x$ & & $x$ & & $x$ & $x$ & & $x^{*}$ & $\times$ & $x$ & $x$ & & & & & \\
\hline \multirow{2}{*}{ Sweden } & Stockholm & $x$ & & & & $x$ & & $x$ & & & & & $x$ & & & $x$ & $x$ \\
\hline & Lund & $x$ & & & & $x$ & & & & 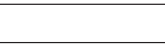 & $x$ & & $x$ & & & $x$ & \\
\hline \multirow{3}{*}{ Turkey } & Istanbul & $x$ & $x$ & $x$ & $x$ & & & & & $x$ & $x$ & $x$ & & & & $x$ & \\
\hline & Izmir & $x$ & & $x$ & $x$ & $\times$ & & $x$ & & $\times$ & $x$ & & & & & & \\
\hline & Ankara & $x$ & & & & $x$ & & & & $x$ & & & & & & & \\
\hline Total & 37 & 30 & 23 & 12 & 11 & 12 & 7 & 10 & 9 & 17 & 12 & 10 & 7 & 7 & 4 & 14 & 3 \\
\hline
\end{tabular}




\section{Application of serological testing}

Participating laboratories were asked to report the purpose of serological testing in use (see section Serological assays used above). In particular 30/36 laboratories declared to use SARS-CoV-2 serological testing as support for seroprevalance studies (Table 3), 22 laboratories as a diagnostic service, 13 laboratories performed serological testing to support collection of the convalescent plasma and 8 as part of larger studies, including also other methodologies of detection (Table 4).

Within these studies or in diagnostic routine, serological testing was used to confirm a past infection in patients without SARS-CoV-2 diagnosis (26 participants from 34), to prove acquired immunity to the infection $(n=15)$, to confirm past infection in those with a negative diagnosis $(n=15)$, to estimate the number of asymptomatic infections $(n=13)$ and to evaluate serological responses in immunocompromised patients $(n=10)$.

Seroprevalence studies performed used several different designs; the descriptive cross-sectional study design was most commonly used followed by cohort study, convenient or probability sampling (Table 3). Targeted sampling was also used. A total of 59 seroprevalence studies were reported as having been performed so far; most of them were focusing on health care workers (HCW, 20 laboratories out of 30), followed by those on general populations (16 laboratories), schools or other institutions (10/30) and blood donors (8/30). Furthermore, $13 \mathrm{HCW}$ studies included health care workers or other personnel such as cleaners, porters, administrative or laboratory staff in hospitals. Other three HCW studies focused on staff members in contact with SARS-CoV-2 infected patients, 2 studies on a specific ward and other 2 on HCW with a previous laboratory confirmed SARS-CoV-2 infection.

Three laboratories reported the observed seroprevalence among HCW; it was 11\% in Belgium, 5\% in Denmark and 22\% in the Netherlands (Table 3). Five out of the 16 laboratories performing seroprevalence studies on general population reported a seroprevalence ranging from 0.88\% in Slovenia to 5.6\% in Belgium and 4 of those laboratories reported also the study population size, which varied from 1368 to 18000 people involved. In particular, Slovenia appeared to have a significantly lower seroprevalence when compared with other countries reporting higher seroprevalences ( $0.88 \%$ vs 2.2 in Denmark, $P=0.001 ; 0.88 \%$ vs $2.9 \%$ in Lisbon $2, P<0.0001 ; 0.88 \%$ vs $2.75 \%$ in Penafiel, $P=0.0001$ ). This difference was also reflected when compared the estimate number of confirmed COVID-19 positive, that was significantly lower in Slovenia (101-1000 cases) compared with Denmark and Portugal that reported $>10000$ cases.

Furthermore, 31 laboratories reported the epidemiological information collected with their serological data (Table 5-8). Most of them collected sample date (26 laboratories), patient's age $(n=28)$, information whether they had a laboratory confirmed SARS-CoV-2 infection and if so, date of diagnosis $(\mathrm{n}=26)$, reported symptoms $(n=22)$, symptom onset $(n=23)$ and severity of infection $(n=14)$ (Table 5). Data collected on severity of infection included whether they were hospitalised $(n=17)$, the length of their hospitals stay $(n=9)$ or whether they were admitted to the intensive care $(n=14)$ (Table 7$)$. Smaller number of laboratories reported data on outcome of the infection ( $n=14$, Table 6) and the presence of underlining medical conditions ( $n=14$, Table 8). Data on long-term outcomes was rarely collected; data on on-going SARS-CoV-2 PCR positivity was collected by 8 laboratories whereas only a few laboratories systematically collected data on long-term respiratory, cardiac or neurological issues ( $\mathrm{n}=2,1$ and 1, respectively; Tables 6, 8).

\section{DISCUSSION}

This study reports data on SARS-CoV-2 serological testing from 36 clinical or public health virological laboratories in 20 European countries. Results demonstrate a rapid European-wide hospital-based response to the COVID-19 pandemic we all faced earlier this year. While these largely hospital-based laboratories were diagnosing and controlling over 100.000 patients with SARS-CoV-2 infection based on defined criteria [6], followed by a variety of mitigation and quarantine strategies often affecting also themselves, they managed simultaneously to introduce a battery of different serological assays not only to clinical practice but also to support seroprevalence studies. Our data shows the variety of assays introduced was vast; from viral isolation to in-house testing and commercial assays, containing different antigens and measuring different antibody classes.

However, during the first wave of COVID-19 pandemic, mitigation strategies were broadly applied without strong evidence to support these [8]. All countries and laboratories participating in our study experienced these mitigation strategies including national and local lockdowns and closures of restaurants, schools or other public places. Measures reflected also the health system capacity, such as observed in Bulgaria where the national lockdown lasted throughout the study period despite the small number of reported SARS-CoV-2 cases. On 


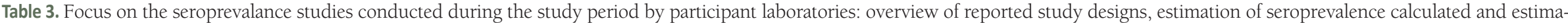
tion of the number of samples included into each study (when available) and/or overall reported in the last column.

\begin{tabular}{|c|c|c|c|c|c|c|c|c|c|c|c|c|}
\hline \multirow[b]{3}{*}{ COUNTRY } & \multirow[b]{3}{*}{ CITY } & \multicolumn{11}{|c|}{ SEROPREVALANCE STUDIES } \\
\hline & & \multicolumn{2}{|c|}{ SCHOOL OR OTHER WORKPLACE } & \multicolumn{2}{|c|}{ HOSPITAL OR GP ASSOCIATED } & \multicolumn{2}{|l|}{ BLOOD DONORS } & \multicolumn{2}{|c|}{ HEALTH CARE WORKERS (HCW) } & \multicolumn{2}{|c|}{ GENERAL POPULATION } & \multirow{2}{*}{$\begin{array}{l}\text { ESTIMATED } \\
\text { NUMBER OF } \\
\text { SAMPLES } \\
\text { INCLUDED }\end{array}$} \\
\hline & & Study design & $\begin{array}{c}\text { Estimated } \\
\text { seroprevalence }\end{array}$ & Study design & $\begin{array}{c}\text { Estimated } \\
\text { seroprevalence }\end{array}$ & Study design & $\begin{array}{c}\text { Estimated } \\
\text { seroprevalence }\end{array}$ & Study design & $\begin{array}{c}\text { Estimated } \\
\text { seroprevalence }\end{array}$ & Study design & $\begin{array}{c}\text { Estimated } \\
\text { seroprevalence }\end{array}$ & \\
\hline Austria & Vienna & $\begin{array}{l}\text { Descriptive } \\
\text { cross-sectional }\end{array}$ & $\begin{array}{l}\text { Manuscript } \\
\text { submitted }\end{array}$ & $\begin{array}{l}\text { Descriptive } \\
\text { cross-sectional }\end{array}$ & $\begin{array}{l}\text { Manuscript } \\
\text { submitted }\end{array}$ & $\begin{array}{l}\text { Cohort; } \\
\text { Descriptive } \\
\text { cross-sectional }\end{array}$ & Study ongoing & $\begin{array}{l}\text { Cohort; } \\
\text { Descriptive } \\
\text { cross-sectional }\end{array}$ & $\begin{array}{l}\text { Manuscript } \\
\text { submitted }\end{array}$ & $\begin{array}{l}\text { Cohort; } \\
\text { Descriptive } \\
\text { cross-sectional }\end{array}$ & $\begin{array}{l}\text { Manuscript } \\
\text { submitted }\end{array}$ & $>5,000$ \\
\hline Belgium & Bruges & & & $\begin{array}{l}\text { Cohort of } \\
\text { dialysis patients }\end{array}$ & $2.5 \%[11]$ & & & $\begin{array}{l}\text { Descriptive } \\
\text { cross-sectional }\end{array}$ & $11 \%$ & $\begin{array}{l}\text { Descriptive } \\
\text { cross-sectional }\end{array}$ & $5.6 \%$ & \\
\hline Bulgaria & Sofia & Unknown & & & & & & Unknown & & & & \\
\hline Croatia & Zagreb & & & Targeted & & & & $\begin{array}{l}\text { Convenient } \\
\text { sampling }\end{array}$ & & $\begin{array}{l}\text { Convenient } \\
\text { sampling }\end{array}$ & & 1.05 \\
\hline $\begin{array}{l}\text { Czech } \\
\text { Republic }\end{array}$ & Prague & $\begin{array}{l}\text { Descriptive } \\
\text { cross-sectional }\end{array}$ & & & & & & Unknown & & & & 460 \\
\hline Denmark & $\begin{array}{l}\text { Copenhagen } \\
\text { and Hilleroed }\end{array}$ & & & & & & & $\begin{array}{l}\text { Cohort; } \\
\text { Descriptive } \\
\text { cross-sectional }\end{array}$ & $5 \%$ & $\begin{array}{l}\text { Descriptive } \\
\text { cross-sectional }\end{array}$ & $2.2 \%$ & $\begin{array}{l}30000 \\
\text { HCW } 18000 \\
\text { general } \\
\text { population }\end{array}$ \\
\hline \multirow{3}{*}{ Germany } & Kiel & & & & & & & & & $\begin{array}{l}\text { Convenient } \\
\text { sampling }\end{array}$ & & \\
\hline & Freiburg & Unknown & Not reported & & & & & Unknown & Not reported & & & 1,000 \\
\hline & Bonn & Unknown & Not reported & & & & & Unknown & Not reported & & & $>4000$ \\
\hline Greece & Crete & & & & & Cohort study & Not reported & Cohort study & Not reported & Cohort study & Not reported & 2,000 \\
\hline Ireland & Dublin & & & & & & & & & $\begin{array}{l}\text { SCOPI study } \\
{[12]}\end{array}$ & & 1,733 \\
\hline Italy & Pavia & $\begin{array}{l}\text { Descriptive } \\
\text { cross-sectional } \\
\text { study }\end{array}$ & Not reported & Unknown & Not reported & Unknown & Not reported & Unknown & Not reported & Unknown & Not reported & 5,000 \\
\hline $\begin{array}{l}\text { The } \\
\text { Netherlands }\end{array}$ & Tilburg & & & & & & & Cohort study & $22 \%$ & & & $\sim 140$ \\
\hline \multirow{2}{*}{ Norway } & Oslo & Unknown & & & & Unknown & & Unknown & & Unknown & & $\sim 4500$ \\
\hline & Trondheim & Unknown & & & & Unknown & & Unknown & & Unknown & & 400 \\
\hline \multirow{5}{*}{ Portugal } & Porto & & & & & $\begin{array}{l}\text { Cohort; } \\
\text { Descriptive } \\
\text { cross-sectional }\end{array}$ & & & & & & 525 \\
\hline & Mora & Unknown & & & & & & & & & & 250 \\
\hline & Lisbon 2 & & & & & & & & & $\begin{array}{l}\text { Convenient } \\
\text { sampling }\end{array}$ & $\begin{array}{l}\text { Seroprevalence } \\
{[2.9 \% \text { IC95(2.0\%- }} \\
4.2 \%)] \text { crude; [1.7 } \\
\text { IC95(0.0 - 3.3)] } \\
\text { adjusted for test } \\
\text { sensitivity }\end{array}$ & 2,300 \\
\hline & $\begin{array}{l}\text { Porto } \\
\end{array}$ & & & & & & & Unknown & & & & 60 \\
\hline & Penafiel & & & & & & & & & $\begin{array}{l}\text { Convenient } \\
\text { sampling }\end{array}$ & $\begin{array}{l}2.7 \% \text { (only igg } \\
\text { was evaluated) }\end{array}$ & 2724 \\
\hline
\end{tabular}




\begin{tabular}{|c|c|c|c|c|c|c|c|c|c|c|c|c|}
\hline \multirow[b]{3}{*}{ COUNTRY } & \multirow[b]{3}{*}{ CITY } & \multicolumn{11}{|c|}{ SEROPREVALANCE STUDIES } \\
\hline & & \multicolumn{2}{|c|}{ SCHOOL OR OTHER WORKPLACE } & \multicolumn{2}{|c|}{ HOSPITAL OR GP ASSOCIATED } & \multicolumn{2}{|l|}{ BLOOD DONORS } & \multicolumn{2}{|c|}{ HEALTH CARE WORKERS (HCW) } & \multicolumn{2}{|c|}{ GENERAL POPULATION } & \multirow{2}{*}{$\begin{array}{l}\text { ESTIMATED } \\
\text { NUMBER OF } \\
\text { SAMPLES } \\
\text { INCLUDED }\end{array}$} \\
\hline & & Study design & $\begin{array}{c}\text { Estimated } \\
\text { seroprevalence }\end{array}$ & Study design & $\begin{array}{c}\text { Estimated } \\
\text { seroprevalence }\end{array}$ & Study design & $\begin{array}{c}\text { Estimated } \\
\text { seroprevalence }\end{array}$ & Study design & $\begin{array}{c}\text { Estimated } \\
\text { seroprevalence }\end{array}$ & Study design & $\begin{array}{c}\text { Estimated } \\
\text { seroprevalence }\end{array}$ & \\
\hline Romania & Bucharest & & & & & & & Cohort study & & & & Not know \\
\hline \multirow{2}{*}{ Slovenia } & Ljubljana 1 & & & & & & & $\begin{array}{l}\text { Descriptive } \\
\text { cross-sectional }\end{array}$ & Still ongoing & & & 1,200 \\
\hline & Ljubljana 2 & & & & & & & & & $\begin{array}{l}\text { Probability } \\
\text { sampling }\end{array}$ & $\begin{array}{l}0.9 \% \text { (late April } \\
2020 \text { ) }\end{array}$ & 1,368 \\
\hline \multirow{3}{*}{ Spain } & Barcelona 1 & & & & & & & Unknown & & & & 7,848 \\
\hline & Barcelona 2 & Cohort study & & & & & & $\begin{array}{l}\text { Descriptive } \\
\text { cross-sectional }\end{array}$ & & Unknown & & 10,000 \\
\hline & Madrid & & & & & Cohort study & & & & Unknown & & 45,000 \\
\hline \multirow{2}{*}{ Sweden } & Stockholm & & & & & & & Unknown & & & & \\
\hline & Lund & & & & & Unknown & & & & & & \\
\hline \multirow[t]{2}{*}{ Turkey } & Istanbul & & & $\begin{array}{l}\text { Descriptive } \\
\text { cross-sectional }\end{array}$ & & & & $\begin{array}{l}\text { Cohort; } \\
\text { Descriptive } \\
\text { cross-sectional }\end{array}$ & & & & 500 \\
\hline & Izmir & & & & & & & & & $\begin{array}{l}\text { Descriptive } \\
\text { cross-sectional }\end{array}$ & & 3,465 \\
\hline Total & & 10 & & 5 & & 8 & & 20 & & 16 & & \\
\hline
\end{tabular}

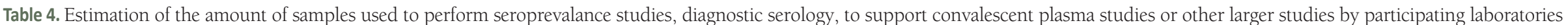
COUNTRY
SEROPREVALANCE STUDIES
DIAGNOSTIC
CONVALESCENT PLASMA
STUDIES
AS SUPPORT FOR LARGER STUDIES
OTHER PURPOSES

Estimate No. samples Estimate No. samples Estimate No. samples

Estimate No. samples

$\begin{array}{llll} & & \text { Multiple evaluation studies for serological assays in acute } \\ \text { infection (n 400) national and local seroprevalence studies } \\ \text { (n } \sim 5000) \text {. Correlation of NT with other assays (n } \sim 500) .\end{array}$

\begin{tabular}{|c|c|c|c|c|c|c|}
\hline Belgium & Bruges & - & 320 & - & - & - \\
\hline $\begin{array}{l}\text { Bosnia and } \\
\text { Herzegovina }\end{array}$ & Sarajevo & - & 561 & - & - & - \\
\hline Bulgaria & Sofia & - & Number not reported & - & - & - \\
\hline Croatia & Zagreb & 1050 & - & - & - & - \\
\hline Czech Republic & Prague & 460 & 100 & 50 & 100 & \\
\hline Denmark 1 & Copenhagen & - & - & - & - & - \\
\hline Denmark 2 & Copenhagen and Hilleroed & $\sim 10000$ & - & - & - & - \\
\hline Germany 1 & Kiel & & $\sim 150$ & - & - & - \\
\hline Germany 2 & Freiburg & 1000 & 500 & 100 & Number not reported & - \\
\hline Germany 3 & Bonn & $>4000$ & $\sim 500$ & $\sim 120$ & - & - \\
\hline
\end{tabular}


Table 4. Continued

\begin{tabular}{|c|c|c|c|c|c|c|}
\hline \multirow[t]{2}{*}{ COUNTRY } & \multirow{2}{*}{ CITY } & \multirow{2}{*}{$\begin{array}{l}\text { SEROPREVALANCE STUDIES } \\
\text { Estimate No. samples }\end{array}$} & DiAgNOSTIC & \multirow{2}{*}{$\begin{array}{l}\text { CONVALESCENT PLASMA } \\
\text { STUDIES } \\
\text { Estimate No. samples }\end{array}$} & \multirow{2}{*}{$\begin{array}{l}\text { AS SUPPORT FOR LARGER STUDIES } \\
\text { Estimate No. samples }\end{array}$} & \multirow{2}{*}{$\begin{array}{l}\text { OTHER PURPOSES } \\
\text { Estimate No. samples }\end{array}$} \\
\hline & & & Estimate No. samples & & & \\
\hline Greece 1 & Thessaloniki & - & - & - & 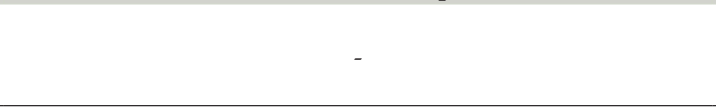 & $\begin{array}{l}\text { To check antibodies kinetics } \\
\text { comparing mild and severe } \\
\text { cases ( } 70 \text { samples) }\end{array}$ \\
\hline Greece 2 & Crete & 2000 & & & Number not reported & - \\
\hline Iceland & Reykjavík & & Number not reported & Number not reported & - & - \\
\hline Ireland & Dublin & 1733 & 2285 & - & - & - \\
\hline Italy & Pavia & 5000 & 20000 & 3900 & $\begin{array}{l}\text { Correlation of NT with other assays }(n \sim 1100) \text { local } \\
\text { seroprevalence studies }(n \sim 1900) \text {. Multiple evaluation studies } \\
\text { for serological assays in acute infection }(n=\sim 400)\end{array}$ & - \\
\hline $\begin{array}{l}\text { The } \\
\text { Netherlands }\end{array}$ & Tilburg & $\sim 140^{*}$ & Number not reported & - & - & $\begin{array}{l}\text { Study on the humoral } \\
\text { immune response in mildly } \\
\text { and severe COVID-19 } \\
\text { patients ( } 62 \text { patients, } 180 \\
\text { samples) }\end{array}$ \\
\hline Norway 1 & Oslo & $\sim 4500$ & $\sim 3500$ & 200 & Number not reported & - \\
\hline Norway 2 & Trondheim & & 400 & 150 & - & - \\
\hline Portugal 1 & Porto & 525 & - & - & - & - \\
\hline Portugal 2 & Mora & 250 & - & - & - & - \\
\hline Portugal 3 & Lisbon 1 & - & - & - & - & - \\
\hline Portugal 4 & Lisbon 2 & 2300 & - & - & - & - \\
\hline Portugal 5 & Porto & 60 & - & - & - & - \\
\hline Portugal 6 & Penafiel & - & 2724 & - & - & - \\
\hline Romania & Bucharest & do not known & - & - & - & - \\
\hline Slovenia 1 & Ljubljana 1 & 1200 & - & - & - & - \\
\hline Slovenia 2 & Ljubljana 2 & 1368 & 250 & & 3,000 & 3100 free-market testing \\
\hline Spain 1 & Barcelona 1 & 7848 & - & - & - & - \\
\hline Spain 2 & Barcelona 2 & 10000 & 1000 & - & - & - \\
\hline Spain 3 & Madrid & 45000 & & $\sim 2000$ & $\begin{array}{l}\text { National seroprevalence study (ENE-COVID) ( } \sim 150000) \text {. } \\
\text { Clinical trial of convalescent Plasma Therapy (ConPlas-19) } \\
\text { (n 2000) }\end{array}$ & $\begin{array}{l}\text { Evaluation of } 21 \text { marketed } \\
\text { serological assays for } \\
\text { determining SARS-CoV-2 } \\
\text { IgG or total antibodies }(\sim 100 \\
\text { samples/test) }\end{array}$ \\
\hline Sweden 1 & Stockholm & & $\begin{array}{l}37000 \text { during April } \\
\text { through June. }\end{array}$ & Data not available & Data not available & - \\
\hline Sweden 2 & Lund & Number not reported & Number not reported & Number not reported & - & - \\
\hline Turkey 1 & Istanbul & 160 & 100 & 400 & - & - \\
\hline Turkey 2 & Izmir & 3465 & 25 & 325 & - & - \\
\hline Turkey 3 & Ankara & & 1200 & 50 & - & - \\
\hline $\begin{array}{l}\text { Total number of } \\
\text { responses }\end{array}$ & & 24 & 22 & 13 & 8 & 4 \\
\hline
\end{tabular}

RESEARCH THEME 1:

COVID-19 PANDEMIC 
Table 5. Description of data about patients' information, collected during seroprevalence studies conducted in Europe, March-June 2020

\begin{tabular}{|c|c|c|c|c|c|c|c|c|c|c|c|}
\hline \multirow{3}{*}{ COUNTRY } & \multicolumn{11}{|c|}{ DATA COLLECTED DURING SEROPREVALENCE STUDIES } \\
\hline & \multirow{2}{*}{$\begin{array}{l}\text { LABORATORY } \\
\text { PERFORMING } \\
\text { SEROPREVALENCE } \\
\text { STUDIES }\end{array}$} & \multicolumn{10}{|c|}{ PATIENT INFORMATION } \\
\hline & & $\begin{array}{l}\text { Whether laboratory } \\
\text { confirmed } \\
\text { diagnosis }\end{array}$ & $\begin{array}{l}\text { Whether } \\
\text { symptomatic }\end{array}$ & $\begin{array}{l}\text { Whether } \\
\text { hospitalised }\end{array}$ & $\begin{array}{l}\text { Which } \\
\text { outcome after } \\
\text { infection }\end{array}$ & $\begin{array}{l}\text { Presence of } \\
\text { underlying } \\
\text { disease }\end{array}$ & $\begin{array}{l}\text { Date of } \\
\text { symptoms } \\
\text { onset }\end{array}$ & $\begin{array}{c}\text { Date of } \\
\text { diagnosis }\end{array}$ & Age & $\begin{array}{l}\text { Date of } \\
\text { sample } \\
\text { collection }\end{array}$ & Other data/ comments \\
\hline Austria & Yes & Yes & Yes & Yes & Yes & Yes & Yes & Yes & Yes & Yes & - \\
\hline Belgium & No & Yes & Yes & Yes & Yes & Yes & No & Yes & Yes & Yes & - \\
\hline $\begin{array}{l}\text { Bosnia and } \\
\text { Herzegovina }\end{array}$ & No & - & - & - & & - & - & - & - & - & - \\
\hline Bulgaria & Yes & Yes & Yes & Yes & Yes & Yes & Yes & Yes & Yes & Yes & - \\
\hline Croatia & Yes & Yes & Yes & Yes & No & Yes & Yes & & No & Yes & - \\
\hline Czech Republic & Yes & Yes & Yes & Yes & Yes & Yes & Yes & Yes & Yes & Yes & - \\
\hline Denmark 1 & No & - & - & - & - & - & - & - & - & - & - \\
\hline Denmark 2 & Yes & Yes & Yes & Yes & Yes & Yes & Yes & Yes & Yes & Yes & $\begin{array}{l}\text { Data on } 2 \mathrm{HCW} \text { studies, but } \\
\text { information not available for } \\
\text { general population based study }\end{array}$ \\
\hline Germany 1 & - & Yes & - & - & - & - & - & Yes & Yes & Yes & - \\
\hline Germany 2 & Yes & Yes & Yes & - & - & Yes & - & & Yes & - & - \\
\hline Germany 3 & Yes & - & - & - & - & - & - & - & - & - & - \\
\hline Greece 1 & No & Yes & Yes & Yes & Yes & Yes & Yes & Yes & Yes & Yes & - \\
\hline Greece 2 & Yes & Yes & Yes & Yes & & Yes & Yes & & Yes & Yes & - \\
\hline Iceland & No & - & - & - & - & - & - & - & - & - & - \\
\hline Ireland & Yes & Yes & Yes & Yes & & & Yes & Yes & Yes & Yes & - \\
\hline Italy & Yes & Yes & Yes & Yes & Yes & Yes & Yes & Yes & Yes & Yes & - \\
\hline The Netherlands & Yes & Yes & Yes & Yes & Yes & Yes & Yes & Yes & Yes & Yes & - \\
\hline Norway 1 & Yes & - & Yes & No & No & No & Yes & Yes & Yes & Yes & - \\
\hline Norway 2 & - & - & - & - & - & - & - & - & - & - & - \\
\hline Portugal 1 & Yes & No & No & No & No & No & No & Yes & Yes & Yes & Only blood donors \\
\hline Portugal 2 & No & Yes & - & Yes & - & - & Yes & Yes & Yes & Yes & Study on residence \\
\hline Portugal 3 & No & - & - & - & - & - & - & Yes & Yes & Yes & - \\
\hline Portugal 4 & Yes & Yes & Yes & No & - & Yes & Yes & Yes & Yes & Yes & - \\
\hline Portugal 5 & Yes & Yes & Yes & Yes & Yes; No & No & Yes & Yes & Yes & Yes & - \\
\hline Portugal 6 & Yes & Yes & Yes & Yes & Yes & Yes & Yes & Yes & Yes & Yes & $\begin{array}{l}\text { Elderly of nursery homes/residences } \\
\text { also studied }\end{array}$ \\
\hline Romania & Yes & Yes & Yes & Yes & Yes & Yes & Yes & Yes & Yes & Yes & - \\
\hline Slovenia 1 & Yes & Yes & Yes & - & - & Yes & Yes & Yes & Yes & Yes & $\begin{array}{l}\text { HCW (including nurses and } \\
\text { doctors from } 2 \text { regional hospitals) }\end{array}$ \\
\hline Slovenia 2 & Yes & Yes & Yes & Yes & - & - & Yes & Yes & Yes & Yes & - \\
\hline Spain 1 & Yes & Yes & Yes & Yes & Yes & - & Yes & Yes & Yes & Yes & - \\
\hline Spain 2 & Yes & Yes & Yes & & - & - & Yes & Yes & Yes & Yes & - \\
\hline Spain 3 & Yes & Yes & Yes & Yes & Yes & - & Yes & Yes & Yes & Yes & - \\
\hline Sweden 1 & No & - & - & - & - & - & - & - & - & - & - \\
\hline Sweden 2 & Yes & Yes & No & No & No & No & Yes & Yes & Yes & Yes & - \\
\hline Turkey 1 & Yes & Yes & - & Yes & - & - & - & Yes & Yes & Yes & - \\
\hline Turkey 2 & Yes & - & - & - & & - & - & - & - & - & No details available at the laboratory \\
\hline Turkey 3 & No & - & - & - & - & - & - & - & - & - & - \\
\hline $\begin{array}{l}\text { Total number } \\
\text { of responses }\end{array}$ & 25 & 26 & 22 & 21 & 14 & 14 & 23 & 26 & 28 & 27 & 2 \\
\hline
\end{tabular}


Table 6. Description of outcome data collected during seroprevalence studies conducted in Europe, March-June 2020

\begin{tabular}{|c|c|c|c|c|c|c|c|c|}
\hline \multirow[b]{2}{*}{ COUntRY } & \multicolumn{8}{|c|}{$\begin{array}{l}\text { DATA COLLECTED DURING SEROPREVALENCE STUDIES } \\
\text { OUTCOME DATA COLLECTED }\end{array}$} \\
\hline & FULLY RECOVERED & $\begin{array}{l}\text { RECOVERED BUT STILL RNA } \\
\text { POSITIVE }\end{array}$ & DEATH & $\begin{array}{l}\text { LONG TERM } \\
\text { RESP ISSUES }\end{array}$ & $\begin{array}{l}\text { LONG TERM } \\
\text { CARDIO ISSUES }\end{array}$ & LONG TERM TIRENESS & $\begin{array}{l}\text { LONG TERM } \\
\text { NEURO }\end{array}$ & OTHER OUTCOME/СOMMENTS \\
\hline Austria & Yes & Yes & Yes & - & - & - & - & - \\
\hline Belgium & Yes & Yes & Yes & - & - & - & - & - \\
\hline Bosnia and Herzegovina & - & - & - & - & - & - & - & - \\
\hline Bulgaria & - & Yes & Yes & Yes & & Yes & - & - \\
\hline Croatia & - & - & - & - & - & - & - & - \\
\hline Czech Republic & Yes & - & - & - & - & - & - & - \\
\hline Denmark 1 & - & - & - & - & - & - & - & - \\
\hline Denmark 2 & Yes & - & - & - & - & - & - & For the hospital studies only \\
\hline Germany 1 & - & - & - & - & - & - & - & - \\
\hline Germany 2 & - & - & - & - & - & - & - & - \\
\hline Germany 3 & - & - & - & - & - & - & - & - \\
\hline Greece 1 & - & - & - & - & - & - & - & - \\
\hline Greece 2 & Yes & - & - & - & - & - & - & - \\
\hline Iceland & - & - & - & - & - & - & - & - \\
\hline Ireland & - & - & - & - & - & - & - & - \\
\hline Italy & Yes & Yes & Yes & - & - & - & - & - \\
\hline The Netherlands & Yes & Yes & - & - & - & - & - & - \\
\hline Norway 1 & - & - & - & - & - & - & - & - \\
\hline Norway 2 & - & - & - & - & - & - & - & - \\
\hline Portugal 1 & - & - & - & - & - & - & - & - \\
\hline Portugal 2 & - & - & - & - & - & - & - & - \\
\hline Portugal 3 & - & - & - & - & - & - & - & - \\
\hline Portugal 4 & - & - & - & - & - & - & - & - \\
\hline Portugal 5 & Yes & - & - & - & - & - & - & - \\
\hline Portugal 6 & Yes & Yes & - & - & - & - & - & - \\
\hline Romania & Yes & - & Yes & & & & - & - \\
\hline Slovenia 1 & - & - & - & - & - & - & - & - \\
\hline Slovenia 2 & - & - & - & - & - & - & - & - \\
\hline Spain 1 & Yes & Yes & - & - & - & - & - & - \\
\hline Spain 2 & - & - & - & - & - & - & - & - \\
\hline Spain 3 & Yes & Yes & Yes & Yes & Yes & Yes & Yes & $\begin{array}{l}\text { ENE-COVID: Data were collected by National Centre } \\
\text { for Epidemiology, Institute of Health Carlos III. Con- } \\
\text { Plas-19: Data were collected by Hospital Universitario } \\
\text { Puerta de Hierro-Majadahonda. }\end{array}$ \\
\hline Sweden 1 & - & - & - & - & - & - & - & \\
\hline Sweden 2 & - & - & - & - & - & - & - & Data not collected \\
\hline Turkey 1 & Yes & & Yes & & - & - & - & \\
\hline Turkey 2 & - & - & - & - & - & - & - & No details available at the laboratory \\
\hline Turkey 3 & - & - & - & - & - & - & - & \\
\hline Total number of responses & 12 & 8 & 9 & 2 & 1 & 2 & 1 & 2 \\
\hline
\end{tabular}

RESEARCH THEME 1:

COVID-19 PANDEMIC 
Table 7. Description of hospitalisation data collected during seroprevalence studies conducted in Europe, March-June 2020

DATA COLLECTED DURING SEROPREVALENCE STUDIES

HOSPITALISATION DATA COLLECT

COUNTRY

HosPItALISATION (NON ICU) NOT HOSPITALISED AdMISSION IN ICU LENGTH OF HOSPITALISATION NOT KNOWN OTHER

\begin{tabular}{|c|c|c|c|c|c|c|}
\hline Austria & Yes & Yes & Yes & Yes & - & - \\
\hline Belgium & Yes & Yes & Yes & Yes & - & - \\
\hline Bosnia and Herzegovina & - & - & - & - & - & - \\
\hline Bulgaria & Yes & Yes & Yes & - & - & - \\
\hline Croatia & Yes & Yes & - & - & - & Only data about hospitalization $(\mathrm{Y} / \mathrm{N})$ \\
\hline Czech Republic & - & Yes & - & - & - & \\
\hline Denmark 1 & - & - & - & - & - & - \\
\hline Denmark 2 & Yes & Yes & Yes & Yes & - & For the hospital studies only \\
\hline Germany 1 & - & Yes & - & - & - & - \\
\hline Germany 2 & Yes & Yes & Yes & Yes & - & - \\
\hline Germany 3 & & & & - & - & - \\
\hline Greece 1 & Yes & Yes & Yes & - & Yes & - \\
\hline Greece 2 & Yes & Yes & Yes & - & - & - \\
\hline Iceland & - & - & - & - & - & - \\
\hline Ireland & - & - & - & - & - & - \\
\hline Italy & Yes & - & Yes & Yes & - & - \\
\hline The Netherlands & Yes & Yes & - & - & - & - \\
\hline Norway 1 & - & - & - & - & - & - \\
\hline Norway 2 & - & - & - & - & - & - \\
\hline Portugal 1 & - & - & - & - & - & - \\
\hline Portugal 2 & - & - & - & - & - & - \\
\hline Portugal 3 & Yes & - & Yes & - & - & - \\
\hline Portugal 4 & - & - & - & - & - & - \\
\hline Portugal 5 & Yes & Yes & - & - & - & - \\
\hline Portugal 6 & - & - & - & - & - & - \\
\hline Romania & Yes & Yes & Yes & Yes & - & - \\
\hline Slovenia 1 & - & - & - & - & - & - \\
\hline Slovenia 2 & Yes & Yes & Yes & Yes & - & - \\
\hline Spain 1 & - & - & - & - & - & - \\
\hline Spain 2 & Yes & Yes & Yes & Yes & - & - \\
\hline Spain 3 & Yes & Yes & Yes & Yes & Yes & $\begin{array}{l}\text { ENE-COVID: Data were collected by National Centre for Epidemiology, Institute } \\
\text { of Health Carlos III. ConPlas-19: Data were collected by Hospital Universitario } \\
\text { Puerta de Hierro-Majadahonda. }\end{array}$ \\
\hline Sweden 1 & - & - & - & - & - & - \\
\hline Sweden 2 & - & - & - & - & - & - \\
\hline Turkey 1 & Yes & Yes & Yes & - & - & - \\
\hline Turkey 2 & - & Yes & - & - & - & - \\
\hline Turkey 3 & - & & - & - & - & - \\
\hline Total number of responses & 17 & 18 & 14 & 9 & 2 & 3 \\
\hline
\end{tabular}


Table 8. Description of risk factors data collected and age-groups included in seroprevalence studies conducted in Europe, March-June 2020

\begin{tabular}{|c|c|c|c|c|c|c|c|c|c|c|c|c|c|c|c|c|}
\hline \multirow[b]{2}{*}{ COUNTRY } & \multicolumn{9}{|c|}{ RISKS DATA COLLECTED } & \multicolumn{7}{|c|}{ AGE-GROUP (YEARS) INCLUDED IN THE STUDY/IES } \\
\hline & HYPERTENSION & DIABETES & $\begin{array}{l}\text { CARDIOVASCULAR } \\
\text { DISEASE }\end{array}$ & $\begin{array}{l}\text { CHRONIC } \\
\text { RESPIRATORY }\end{array}$ & $\begin{array}{l}\text { CHRONIC } \\
\text { KIDNEY }\end{array}$ & $\begin{array}{l}\text { IMMUNE } \\
\text { COMPROMISED }\end{array}$ & CANCER & OBESITY & ОtheR & $0-4$ & 5-9 & 10-19 & $20-59$ & $60-74$ & $75-90$ & $>90$ \\
\hline Austria & Yes & Yes & Yes & Yes & Yes & Yes & Yes & Yes & - & - & Yes & Yes & Yes & Yes & Yes & Yes \\
\hline Belgium & - & - & - & - & Yes & - & - & - & $\mathrm{HCW}$ & - & - & - & Yes & Yes & Yes & Yes \\
\hline $\begin{array}{l}\text { Bosnia and } \\
\text { Herzegovina }\end{array}$ & - & - & - & - & - & - & - & - & - & - & - & - & - & - & - & - \\
\hline Bulgaria & - & - & - & - & - & Yes & - & - & Haematological & - & - & - & Yes & Yes & Yes & - \\
\hline Croatia & - & - & - & - & - & - & - & - & Data not systematically collect & Yes & Yes & Yes & Yes & Yes & Yes & - \\
\hline Czech Republic & - & - & - & - & - & - & - & - & No criteria of inclusion & - & & & Yes & Yes & Yes & - \\
\hline Denmark 1 & - & - & - & - & - & - & - & - & - & - & - & - & - & - & - & - \\
\hline Denmark 2 & Yes & Yes & Yes & Yes & Yes & Yes & Yes & Yes & For the hospital studies only & - & - & Yes & Yes & Yes & Yes & Yes \\
\hline Germany 1 & - & - & - & - & - & - & - & - & - & - & - & Yes & Yes & Yes & Yes & - \\
\hline Germany 2 & - & - & - & - & - & - & - & - & - & - & Yes & Yes & Yes & Yes & Yes & - \\
\hline Germany 3 & - & - & - & - & - & - & - & - & - & - & - & Yes & Yes & Yes & Yes & - \\
\hline Greece 1 & - & - & - & - & - & - & - & - & - & - & - & - & Yes & Yes & Yes & - \\
\hline Greece 2 & - & - & - & - & - & - & - & - & - & - & - & - & Yes & Yes & Yes & - \\
\hline Iceland & - & - & - & - & - & - & - & - & - & - & - & - & - & - & - & - \\
\hline Ireland & - & - & - & - & - & - & - & - & - & - & - & - & - & - & - & - \\
\hline Italy & - & - & - & - & - & - & - & - & - & - & - & - & Yes & Yes & Yes & - \\
\hline The Netherlands & - & - & Yes & Yes & - & Yes & Yes & Yes & Questionnaire about risk factors & - & - & - & Yes & Yes & - & . \\
\hline Norway 1 & - & - & - & - & - & - & - & - & - & - & Yes & Yes & Yes & Yes & Yes & - \\
\hline Norway 2 & - & - & - & - & - & - & - & - & - & - & - & - & - & - & - & - \\
\hline Portugal 1 & - & - & - & - & - & - & - & - & - & - & - & Yes & Yes & Yes & - & - \\
\hline Portugal 2 & - & - & - & - & - & - & - & - & - & - & - & - & - & - & - & - \\
\hline Portugal 3 & - & - & - & - & - & - & - & - & - & Yes & Yes & Yes & - & - & - & - \\
\hline Portugal 4 & Yes & Yes & Yes & Yes & Yes & Yes & Yes & Yes & - & Yes & Yes & Yes & Yes & Yes & Yes & Yes \\
\hline Portugal 5 & - & - & - & - & - & - & - & - & $\begin{array}{l}\text { HCW with previously positive } \\
\text { real time PCR were included }\end{array}$ & - & - & - & Yes & Yes & - & - \\
\hline Portugal 6 & Yes & Yes & Yes & Yes & Yes & - & Yes & - & $\begin{array}{c}\text { Questionnaires about risk } \\
\text { factors were performed. Elderly } \\
\text { from nursery homes/residences } \\
\text { were also considered }\end{array}$ & Yes & Yes & Yes & Yes & Yes & Yes & Yes \\
\hline Romania & Yes & Yes & Yes & Yes & Yes & Yes & Yes & Yes & - & - & - & - & Yes & Yes & - & - \\
\hline Slovenia 1 & Yes & Yes & Yes & Yes & Yes & Yes & Yes & - & HCW & - & - & - & Yes & Yes & - & - \\
\hline Slovenia 2 & - & - & - & - & - & - & - & - & - & Yes & Yes & Yes & Yes & Yes & Yes & Yes \\
\hline Spain 1 & - & - & - & - & - & - & - & - & - & - & - & - & Yes & - & - & - \\
\hline
\end{tabular}




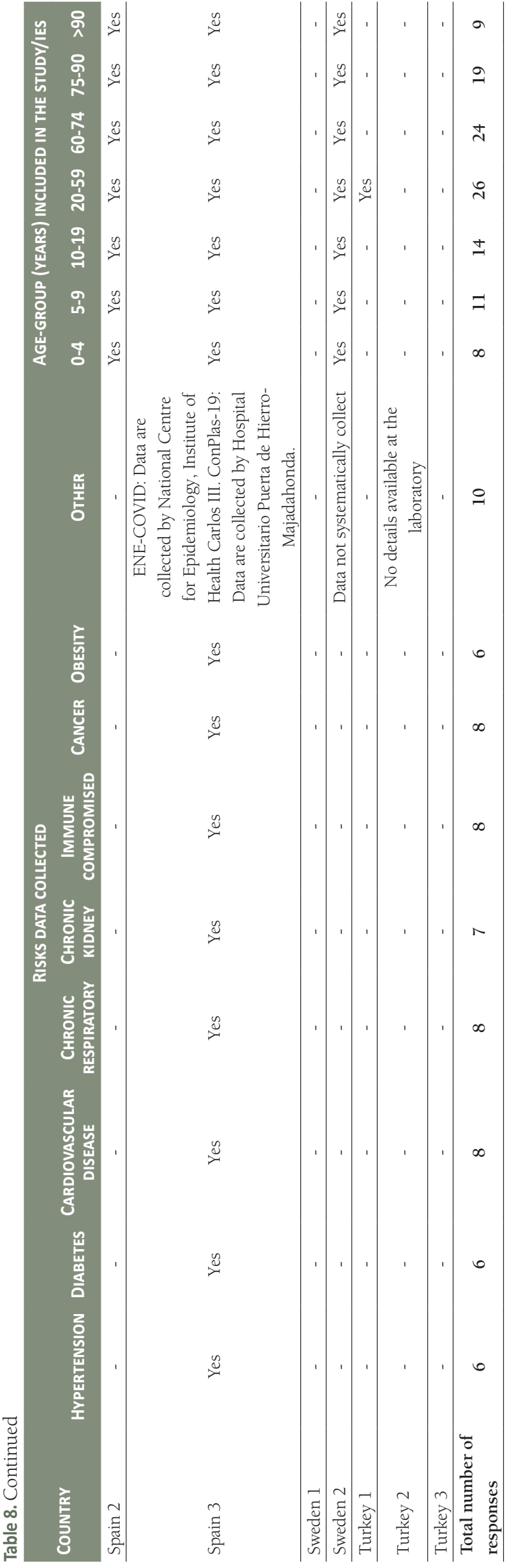

the contrary, Sweden with over 15000 SARS-CoV-2 infections, choose to recommend social distancing only including limiting the gatherings to maximum 50 people, working from home and restricting access to care-homes, in line with the ECDC guidance [13]. Along with mitigation strategies, most participating $(94 \%, 34 / 36)$ reported also the use of quarantine scheme after a suspected contact with a SARSCoV-2 positive person, a travel within or beyond the Europe, with the majority of responders indicating 14 days as period of observation as recommended by ECDC [14]. The length of quarantine was also in keeping with suggested SARS-CoV-2 incubation period $[15,16]$. It is clear from our data that about $80 \%$ of regions/countries observed a decrease in the number of reported SARS-CoV-2 cases within the first 60 days of national lockdown.

This pandemic has also demonstrated the fast tempo serological assays are needed, and can be developed, to support investigations into a newly emerged virus, such as SARS-CoV-2 here. To date, 10 months from the first diagnosis in Europe, about 200 commercial assays have been introduced into the European market [17] and the number continues to increase. Although the clinical and research needs for such assays cannot be over-stated, it is important to maintain quality standards in clinical laboratories. For these reasons, we need to consider how the international community can reach out and support the diagnostic laboratories during these challenging times. In our series of laboratories, validation or verification of the assays prior to their introduction into routine work was largely undertaken. However, the number of samples used for the validation was limited in some cases (ie, below 15 in total) and some laboratories did not have access to reference material in order to perform the assay validation. However, their responses indicated understanding of general good laboratory practice. In fact, proper validation prior the use of a new commercial assay should be always performed, but as openly declared from one of participant, during the first pandemic wave laboratories were overwhelmed due to the amount of work requested and hence had to postpone the validation for practical reasons. The guidance on assay validation is limited, but it should also be modified according to specific situation such as pandemic. Furthermore, informal hospital-based laboratory networks should be encouraged as they can be a source of technical and material support during difficult times, like this pandemic.

Although we did not aim to evaluate the results obtained by different serological assays in this study, it is vital to point out that the sensitivity and specificity of available SARS-CoV-2 serological assays varies hugely [18]. For example, the sensitivity of some most commonly used assays does not reach even 80\% [19]. However, serological assays have different require- 
ment depending on their purpose. Whereas the ease of use might be the most important criteria if an assay is being used for a large-scale seroprevalence work, sensitivity is a key marker for any assay used diagnostically. Any assay used to screen convalescent plasma donors should be predictive of high neutralising antibody levels. Anticipated SARS-CoV-2 vaccine introduction into routine use will set up further requirements for serological assays used, especially when we need to evaluate separately vaccine-produced and natural immunity. This would mean that laboratories may need to consider setting up at least two serological assays, one focusing on antibodies directed against spike protein and another against nucleocapsid proteins. Based on our data, over half of laboratories participating to our study do not currently have both of these assays available, but by introducing an additional test they could easily support the introduction of vaccine.

More than half of participating laboratories performed one or more seroprevalance studies, mostly focusing on specific population such as health care workers and blood donors. With these studies, information on age, date of sample collection and diagnosis were almost always gathered, whereas the outcome data and information on underlying diseases were less frequently collected. [20]. This could be a limitation in understanding risk factors driving a different immunological response. In fact, despite it is quite clear that the presence of some diseases can increase the risk of severe outcomes [18], their role in the immune response remain unclear [21]. Although our current understanding of immunological responses to SARS-CoV-2 including the durability of the antibody response and occurrence of seroreversion remains uncertain $[22,23]$, continuation of seroprevalance studies collecting more information of medical conditions is highly recommended. Such studies will provide better understanding of the pandemic course in the coming months in the absence of a protective vaccine and the necessity to target public health measures to specific populations at highest risk.

Estimation of seroprevalance in general population was reported by five participant laboratories in this study, and similarly seroprevalence among HCW was reported by three participant laboratories only. Although it was clear, that seroprevalence was higher among the HCW than in general population, confirming the previous observations [24], it is not possible to draw further conclusions from these data. We collected only limited information about the characteristics of the study population (ie, age, symptoms), details about the serological test used (ie, manufacturer, antigen and antibody subclass) and the dates of study. Although the same limitations applied to the population-based seroprevalance studies reported here, the seroprevalence estimates were in line with the number of SARS-CoV-2 infections reported during the same period from the same region hence reflecting the country-based situation well.

We have described the SARS-CoV-2 serological testing introduced and undertaken across the 36 different European laboratories during the first pandemic wave, when there was the urge to understand the seroprevalance of affected populations, the length of immunity acquired during SARS-CoV-2 infections and its likely protective effects. This understanding is still required and would likely support the public health decision making and drive evidence-based mitigation and infection control strategies.

\section{CONCLUSION}

This is the first paper, to our knowledge, gathering the information available in the European region about the use of serological testing during the first pandemic wave. The study documents the high level of hospital-laboratory involvement in serological response across European countries during the first pandemic wave: serology methods were rapidly implemented by many hospital laboratories and served as an important diagnostic supplement while the molecular diagnostic capacity increased during these early months of the first pandemic wave.

Note added in proof: The probability-based seroprevalence study in Slovenia (Table 3, Ljubljana 2) is now published [25].

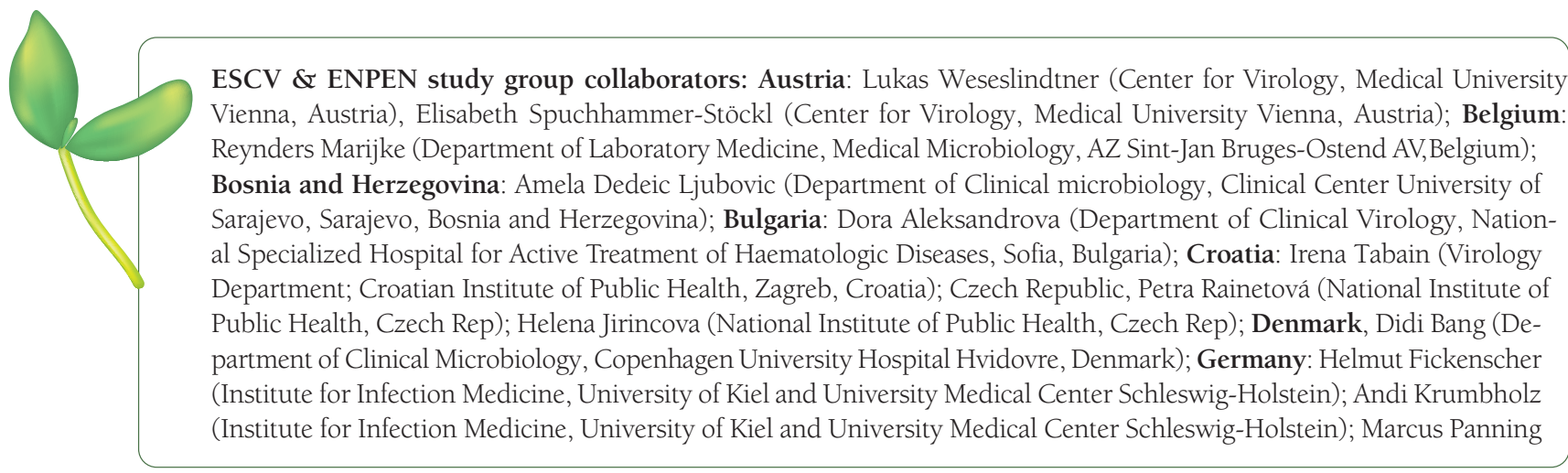


(Institute of Virology, Freiburg University Medical Center, Faculty of Medicine, University of Freiburg, Freiburg, Germany); Daniela Huzly (Institute of Virology, Freiburg University Medical Center, Faculty of Medicine, University of Freiburg, Freiburg, Germany); Anna M. Eis-Hübinger (Institute of Virology, University Hospital, University of Bonn, Bonn, Germany), Greece: Anna Papa (Department of Microbiology, Medical School, Aristotle University of Thessaloniki, Thessaloniki, Greece); George Sourvinos (Laboratory of Clinical Virology, Medical School, University of Crete, Herakleion, Crete, Greece); Alexandros Zafiropoulos (Laboratory of Clinical Virology, Medical School, University of Crete, Herakleion, Crete, Greece); Iceland: Ásgeir Erlendur Ásgeirsson (Department of Clinical Microbiology Landspitali-National University Hospital of Iceland); Ireland: Jeff Connell (University College Dublin, National Virus Reference Laboratory, University College Dublin, Belfield, Dublin 4); Italy: Elena Percivalle (Molecular Virology Unit, Department of Microbiology and Virology, IRCCS Fondazione Policlinico San Matteo, Pavia, Italy); Irene Cassaniti (Molecular Virology Unit, Department of Microbiology and Virology, IRCCS Fondazione Policlinico San Matteo, Pavia, Italy); Netherlands: Couderé Karen (Microvida, Elisabeth-Tweesteden Hospital, Tilburg, The Netherlands); Norway, Andreas Lind (Department of Microbiology, Oslo University Hospital, Oslo, Norway); Svein Arne Nordbø (Department of Medical Microbiology, St. Olavs University Hospital, Trondheim, Norway and Department of Clinical; Molecular Medicine, Norwegian University of Science and Technology, Trondheim, Norway); Portugal: Maria de São José Nascimento (Faculty of Pharmacy, University of Porto, Porto, Portugal), João Rodrigo Mesquita (Abel Salazar Institute of Biomedical Sciences, University of Porto, Porto, Portugal); Carlos Sinogas (Évora University, Biology Department); Maria Brito (Infectious Pediatric Unit. Department of Pediatrics. Hospital de Dona Estefânia. CHULC. Lisbon. Portugal); Raquel Guiomar (Infectious Diseases Department, National Institute of Health Dr Ricardo Jorge, Lisbon, Portugal); Ana Paula Rodrigues (Epidemiology Department, National Institute of Health Dr Ricardo Jorge, Lisbon, Portugal), Daniela Fonseca e Silva (Instituto Português de Oncologia Francisco Gentil Porto, E.P.E, Porto, Portugal), Ana Abreu (Director of the Laboratory of Clinical Analysis Vale do Sousa), Paulo Dessa (Laboratório de Análises Clínicas Vale do Sousa, Penafiel, Portugal); Romania: Corneliu Petru Popescu (Carol Davila University of Medicine and Pharmacy, Bucharest, Romania), Victor Babes (Clinical Hospital of Infectious and Tropical Diseases, Bucharest, Romania); Slovenia, Natasa Berginc (National Laboratory for Health, Environment and Food, Laboratory for Public Health Virology, Ljubljana, Slovenia), Katarina Prosenc Trilar (National Laboratory for Health, Environment and Food, Laboratory for Public Health Virology, Ljubljana, Slovenia), Mario Poljak (Institute of Microbiology and Immunology, Faculty of Medicine, University of Ljubljana, Slovenia); Spain: Núria Rabella (Virology Unit, Department of Clinical Microbiology, Hospital Universitari de la Santa Creu i Sant Pau. Universitat Autònoma de Barcelona. Barcelona, Spain), Juliana Esperalba (Microbiology Department, Vall d'Hebron Institut de Recer-ca (VHIR), Vall d'Hebron Hospital Universitari, Barcelona, Spain), Mayte Pérez-Olmeda (Serology Laboratory. National Center of Microbiology. Institute of Health Carlos III. Madrid, Spain), Aurora Fernández-García (Serology Laboratory. National Center of Microbiology. Institute of Health Carlos III . Madrid, Spain; Consortium for Biomedical Research in Epidemiology and Public Health (CIBERESP). Institute of Health Carlos III . Madrid, Spain); Sweden: Gordana Bog-danovic (Department of Clinical Microbiology, Karolinska University Hospital, Stockholm, Sweden), Sandra Muschiol (Department of Clinical Microbiology, Karolinska University Hospital, Stockholm, Sweden), Claus Bohn Christiansen (Department of Clinical Microbiology, Medical Service, Region Skåne, Lund, Sweden); Turkey: Rabia Can Sarınoglu (Department of Medical Microbiology, Marmara University Pendik Training and Research Hospital, Istanbul, Turkey), Aysegul Karahasan Yagci (Department of Medical Microbiology, Marmara University Pendik Training and Research Hos-pital, Istanbul, Turkey), Aysin Zeytinoglu (Department of Medical Microbiology, Ege University Medical Faculty, Izmir, Turkey), Mehmet Soylu (Department of Medical Microbiology, Ege University Medical Faculty, Izmir, Turkey), Burcin Sener (Department of Medical Microbiology, Faculty of Medicine, Hacettepe University, Ankara, Turkey), Alpaslan Alp (Department of Medical Microbiology, Faculty of Medicine, Hacettepe University, Ankara, Turkey).

Acknowledgements: Approval from an ethics committee and informed consent for virus detection and data publication were not required since data were reported as aggregate and anonymous. All authors and study group authors declared the access to the data and the permission to share their content for the publication. We acknowledge the sup-port of ESCV (European society for Clinical virology) in granting a research fellowship, with no involvement in data analysis, drafting of the manuscript and publication. Laboratories' authors would like to thank and to acknowledge: Germany: Kiel: We would like to acknowledge the work of Annabelle Strömer and Ruben Rose. Freiburg: The study was funded by the Federal Ministry of Education and Research (grant No. 01 KI1722 to MP). Greece: Crete: Funded by the National Public Investment Program of the Ministry of Development and Investment / General Secretariat for Re-search and Technology in the framework of the Flagship Initiative to address SARS-CoV-2 (2020EE01300001). Portu-gal: Porto 1: MSJN and JRM would like to thank Fundação para a Ciência e para a Tecnologia for project "SARS-CoV-2 and blood donation safety in Portugal: a shift to screening? SARSBLOODsafe" (ref 021_596187412) under the call RESEARCH 4 COVID-19. Porto 2: CS would like to thank the laboratory staff of Virology Department IPOFGP, Porto, Portugal. Portugal 3: MB would like to thank the laboratory staff of Centro Hospitalar Lisboa Central. Lisbon. Portugal. Romania: To laboratory staff of Victor Babes Hospital, Bucharest, Romania. Spain: Barcelona: All staff from Clinical Laboratory of Vall d'Hebron Hospital Universitari, Barcelona, Spain. Madrid: 1) ENE-COVID Study Group (work sup-ported by the Spanish Ministry of Health, the Institute of Health Carlos III (Ministry of Science and Innovation), and the National Health System. 2) ConPlas-19 Study Group (work supported by the Institute of Health Carlos III (Minis-try of Science and Innovation).

Funding: ESCV granted a research fellow to support data collection and elaboration. 
Authorship contributions: HH and TKF contributed to the study conception and design. Material preparation, data collection and analysis were performed by LB, such as the first draft of the manuscript. TKF, PS, HH critically revised the data and manuscript. All study group authors commented on previous versions of the manuscript, collected and shared data from their laboratories, checking the content of the manuscript. All authors read and approved the final manuscript.

Competing interests: The authors completed the ICME Unified Competing Interest form (available upon request from the corresponding author) and declare no conflict of interest.

1 European Centre of Disease Control. Number of cases and deaths in Europe. Available: https://www.ecdc.europa.eu/en/geographical-distribution-2019-ncov-cases. Accessed: 15 April 2021.

2 Richardson S, Hirsch JS, Narasimhan M, Crawford JM, McGinn T, Davidson KW, et al. Presenting Characteristics, Comorbidities, and Outcomes Among 5700 Patients Hospitalized With COVID-19 in the New York City Area. JAMA. 2020;323:2052-9. Erratum in: JAMA. 2020;323:2098. Medline:32320003 doi:10.1001/jama.2020.6775

3 Slot E, Hogema BM, Reusken CBEM, Reimerink JH, Molier M, Karregat JHM, et al. Low SARS-CoV-2 seroprevalence in blood donors in the early COVID-19 epidemic in the Netherlands. Nat Commun. 2020;11:5744. Medline:33184284 doi:10.1038/ s41467-020-19481-7

4 Istituto Nazionale di Statistica (ISTAT). Available: https://www.istat.it/it/archivio/246156. Accessed: 15 April 2021.

5 Pollán M, Pérez-Gómez B, Pastor-Barriuso R, Oteo J, Hernán MA, Pérez-Olmeda M, et al. Prevalence of SARS-CoV-2 in Spain (ENE-COVID): a nationwide, population-based seroepidemiological study. Lancet. 2020;396:535-44. Medline:32645347 doi:10.1016/S0140-6736(20)31483-5

6 World Health Organization. Case number dashboard. Available: https://covid19.who.int/ Accessed: 15 April 2021.

7 Harvala H, Robb ML, Watkins N, Ijaz S, Dicks S, Patel M, et al. Convalescent plasma therapy for the treatment of patients with COVID-19: Assessment of methods available for antibody detection and their correlation with neutralising antibody levels. Transfus Med. 2020. Online ahead of print. Medline:33333627 doi:10.1111/tme.12746

8 Lisboa Bastos M, Tavaziva G, Abidi SK, Campbell JR, Haraoui LP, Johnston JC, et al. Diagnostic accuracy of serological tests for covid-19: systematic review and meta-analysis. BMJ. 2020;370:m2516. Medline:32611558 doi:10.1136/bmj.m2516

9 Strömer A, Rose R, Grobe O, Neumann F, Fickenscher H, Lorentz T, et al. Kinetics of nucleo- and spike protein-specific immunoglobulin G and of virus-neutralizing antibodies after SARS-CoV-2 infection. Microorganisms. 2020;8:1572. Medline:33066057 doi:10.3390/microorganisms8101572

10 Nie J, Li Q, Wu J, Zhao C, Hao H, Liu H, et al. Establishment and validation of a pseudovirus neutralisation assay for SARSCoV-2. Emerg Microbes Infect. 2020;9:680-6. Medline:32207377 doi:10.1080/22221751.2020.1743767

11 De Vriese AS, Reynders M. IgG Antibody Response to SARS-CoV-2 Infection and Viral RNA Persistence in Patients on Maintenance Hemodialysis. Am J Kidney Dis. 2020;76:440-1. doi:10.1053/j.ajkd.2020.05.009. Medline:32512038

12 Ireland HSE. https://www.hse.ie/eng/services/news/newsfeatures/scopi-covid-19-research-project/ Accessed: 15 April 2021.

13 ECDC. mitigation strategies: https://www.ecdc.europa.eu/sites/default/files/documents/covid-19-guidelines-non-pharmaceutical-interventions-september-2020.pdf Accessed: 15 April 2021.

14 ECDC quarantine strategies. Available: https://www.ecdc.europa.eu/sites/default/files/documents/Leaflet-Covid-19_Isolation-and-quarantine.pdf. Accessed: 15 April 2021.

15 Backer JA, Klinkenberg D, Wallinga J. Incubation period of 2019 novel coronavirus (2019-nCoV) infections among travellers from Wuhan, China, 20-28 January 2020. Euro Surveill. 2020;25:2000062. Medline:32046819 doi:10.2807/1560-7917. ES.2020.25.5.2000062

16 Kim D, Quinn J, Pinsky B, Shah NH, Brown I. Rates of Co-infection Between SARS-CoV-2 and Other Respiratory Pathogens. JAMA. 2020 323:2085-86. Medline:32293646 doi:10.1001/jama.2020.6266

17 European Commision. Annex 1: commercial devices, type Immunoassay. Available: https://ec.europa.eu/docsroom/documents/40805. Accessed: 15 April 2021.

18 FIND. comparison of commercial serological assay https://www.finddx.org/covid-19/sarscov2-eval-antibody/ Accessed: 9 January 2021.

19 Haselmann V, Özçürümez MK, Klawonn F, Ast V, Gerhards C, Eichner R, et al. Results of the first pilot external quality assessment (EQA) scheme for anti-SARS-CoV2-antibody testing. Clin Chem Lab Med. 2020;58:2121-30. Medline:32853163 doi:10.1515/cclm-2020-1183

20 Ko JY, Danielson ML, Town M, Derado G, Greenlund KJ, Kirley PD, et al. Risk Factors for COVID-19-associated hospitalization: COVID-19-Associated Hospitalization Surveillance Network and Behavioral Risk Factor Surveillance System. Clin Infect Dis. 2020. Online ahead of print. Medline:32945846

21 Sattler A, Angermair S, Stockmann H, Heim KM, Khadzhynov D, Treskatsch S, et al. SARS-CoV-2 specific T-cell responses and correlations with COVID-19 patient predisposition. J Clin Invest. 2020;130:6477-89. Medline:32833687 doi:10.1172/JCI140965

22 Grifoni A, Weiskopf D, Ramirez SI, Mateus J, Dan JM, Moderbacher CR, et al. Targets of T Cell Responses to SARS-CoV-2 Coronavirus in Humans with COVID-19 Disease and Unexposed Individuals. Cell. 2020;181:1489-1501.e15. Medline:32473127 doi:10.1016/j.cell.2020.05.015

23 Braun J, Loyal L, Frentsch M, Wendisch D, Georg P, Kurth F, et al. Presence of SARS-CoV-2 reactive T cells in COVID-19 patients and healthy donors. Nature. 2020;587:270-4. Medline:32726801 doi:10.1038/s41586-020-2598-9

24 Piccoli L, Ferrari P, Piumatti G, Jovic S, Fernandez Rodriguez B, Mele F, et al. Risk assessment and seroprevalence of SARSCoV-2 infection in healthcare workers of COVID-19 and non-COVID-19 hospitals in Southern Switzerland. Lancet Regional Health - Europe. 2021;1:100013. doi:10.1016/j.lanepe.2020.100013

25 Poljak M, Oštrbenk Valenčak A, Štrumbelj E, Maver Vodičar P, Vehovar V, Resman Rus K, et al. Seroprevalence of severe acute respiratory syndrome coronavirus 2 in Slovenia: results of two rounds of a nationwide population study on a probability-based sample, challenges and lessons learned. Clin Microbiol Infect. 2021. Online ahead of print. Medline:33838303 doi:10.1016/j.cmi.2021.03.009 